\title{
Determinants of Inflation in Palestine
}

Bahaaeddin Alareeni*

University College of Applied Sciences,

Gaza Strip, Palestine

Email: bahaaedu@hotmail.com

\section{Nariman Qdeh}

University College of Applied Sciences,

Gaza Strip, Palestine

Email: nariman.hq018@gmail.com

\section{Mohammed Salem Lulu}

Ministry of Agriculture,

Gaza Strip, Palestine

Email: salemlulu@ @otmail.com

\section{Received May, 2018; Accepted September, 2018}

\begin{abstract}
This study aimed at identifying the most important determinants and economic factors affecting inflation rates in Palestine during the period (2000-2014), in order to help in reducing its effects on the Palestinian economy. The descriptive and analytical approach was used, by selecting a set of variables that were expected to have an impact on the inflation rates in the Palestinian economy, as these factors were as economic growth rate, interest rate, exchange rate, unemployment rate, money supply, wages, the inflation rate in Israel, and the global inflation rate. Two statistical models were developed for West Bank and Gaza Strip separately, based on quarter time series data for determinants of inflation in the Palestinian economy for the period from 2000-2014. The results showed the significant impact of: (the exchange rate, the Israeli inflation rate, the economic growth rate) on the inflation rate in the West Bank. In addition, it showed the significant effect of: (global inflation rate, unemployment rate, the economic growth rate) on the inflation rate in Gaza Strip. The other variables: credit facility, wage rate , and interest rate were statistically insignificant. In light of this, the study recommended the necessity of issuing a national currency to reduce the losses of the Palestinian economy due to the absence of the national currency, as well as the pressure of imports and trying to find local alternatives by supporting the national product, as well as the need to review trade and economic policies between the Palestinian Authority and Israel to serve the development of the Palestinian economy.
\end{abstract}

Keywords: Inflation Rate; Economic Growth Rate; Palestine

Type: research paper

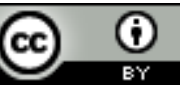

This work is licensed under a Creative Commons Attribution 4.0 International License.

\section{DOI: 10.51325/ijbeg.v1i3.43}


تمثلت هذه العوامل في (معدل النمو الاقتصادي، سعر الفائدة، سعر الصرف، معدل البطالة، عرض النقد، معدل

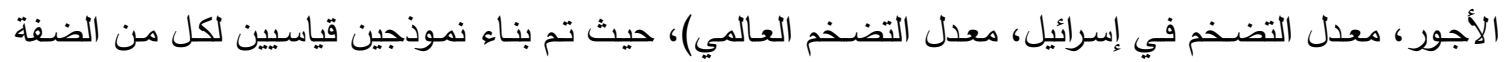

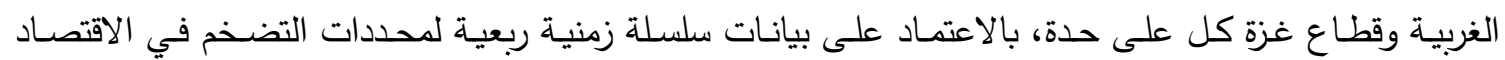
الفلسطيني للفترة الزمنيـة (2000-2014)، وتم الاستعانة بالبرنـامج الإحصـائي EViews لإيجـاد العلاقـة بـين

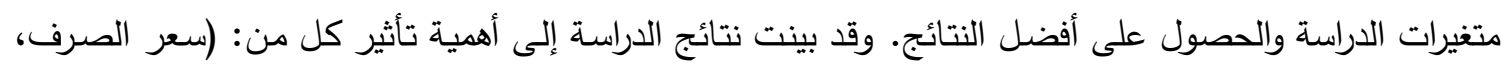
معدل التضخم الإسرائيلي، معدل النمو الاقتصـادي) على معدل التضخم في الضفة الغربية حيث بلـغ معامل كل منهم (2.1-، 0.62، 0.081-) على التوالي، وكذلك بينت نتائج الدراسة أهمية تأثير كل من: (معدل التضخدم العالمي، معدل البطالة، معدل النمو الاقتصادي) على معدل التضخم في قطاع غزة حيث بلغ معامل كل منهم (1.47، 0.07، 0.03-) على التوالي، بينما كان كل من المتغيرات الأخرى: التسهيلات الائتمانية، معدل الأجور

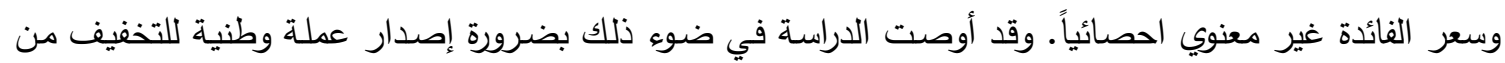
خسائر الاقتصاد الفلسطيني جراء عدم وجود العملة الوطنية، أيضاً ضغط الواردات ومحاولة ايجاد البدائل المحلية

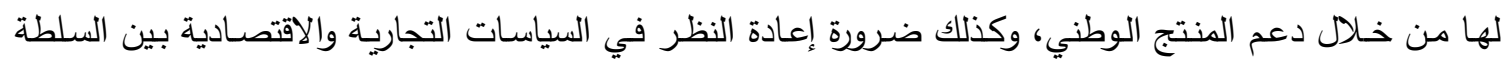

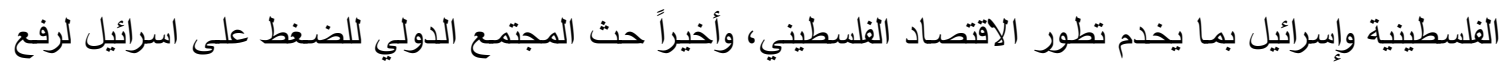
الحصار المفروض على قطاع غزة.

الكلمات المفتاحية: محددات التضخم، الأرقام القياسية للأسعار

المقدمة

تعتبر مشكلة التضخم قديمة قدم المال نفسه، حيث ارتبطت هذه المشكلة بالتطور التاريخي لإصدار النقود ولتتامي حاجات ورغبات سكان المعمورة، ومع التعقيدات المستمرة في طبيعة المجتمعات وتثابك حاجاتهم ظهرت الحاجة

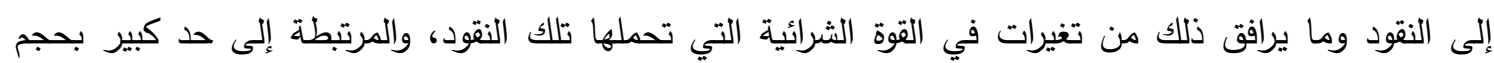
الإنتاج والطلب على ما تتتجه المجتمعات منذ الأزل. حيث يعتبر التضخم في الآونة الأخيرة أكثر تعقيداً كونه

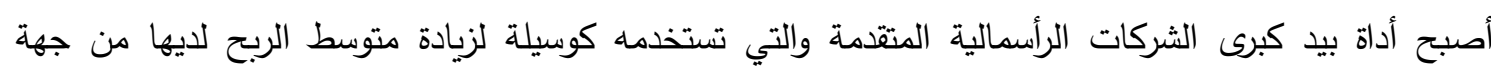
واستغلال مقومات الثعوب وتحديداً الدول النامية من جهة أخرى، حيث أن الدول النامية تعاني من تراجع مستويات

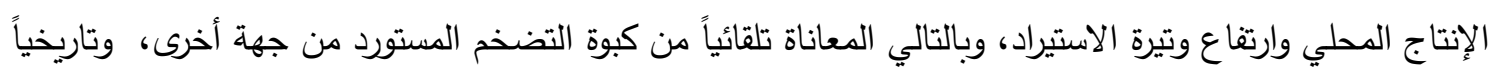

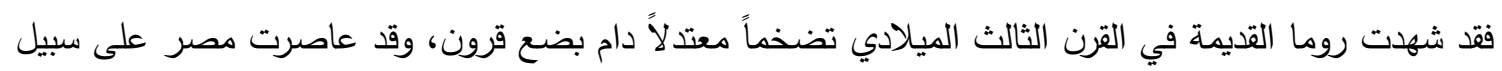

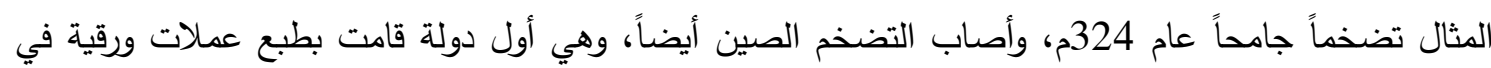
القرن الحادي عشر (التمويل والتتمية، 2003).

وعبر السنوات، تفاقمت مشكلة التضخم وأصبحت مشكلة ذات بعد وتأثير عالمي بعد تخلي الولايات المتحدة

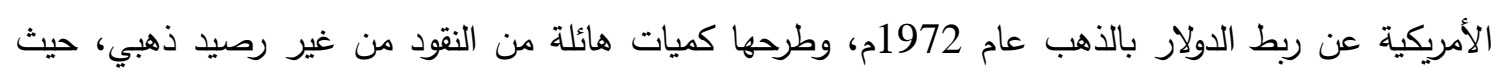
استمر الارتفاع في المستوى العام للأسعار حتى الوقت الراهن وبوتيرة سريعة وساهم ذلك بتراجع مستويات الرفاه

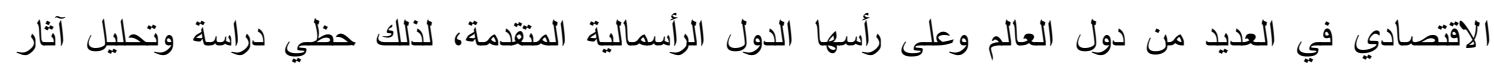

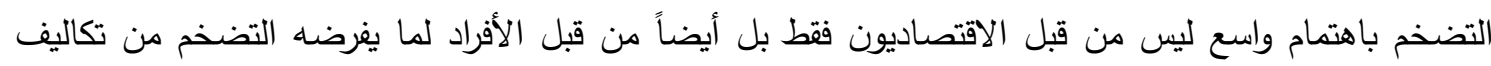

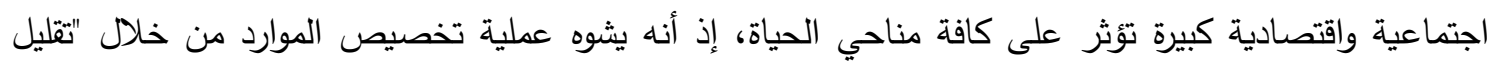


معلومات" نظام الأسعار، مما يؤثر سلباً على الكفاءة الاقتصادية والنمو، كما يؤدي التضخم إلى توزيع عشوائي للاخل والثروة في المجتمع، ومن ثم التأثير على الرفاه الاجتماعي (1996، IMF).

وعلى الرغم من الاهتمام المتزايد من قبل الاقتصاديين والعلماء بهذه الظاهرة، إلا أن الجدل مازال قائماً حول الأسباب والعوامل الكامنة وراء حدوث التضخم وآثاره الاقتصادية على النظام الاقتصادي، وهل تختلف هذه العنداء العوامل من دولة إلى أخرى ومن زمن إلى آخر ، وماهي أنسب السياسات الاقتصادية التي من الممكن اتباعها لكبح جِماحها كالسياسات المالية والنقدية والتجارية. وتعتبر الأراضي الفلسطينية أحد البلدان النامية التي تعاني من ظاهرة التضخم، وتثير سلطة النقد الفلسطينية في تقاريرها حول التضخم، بأن التضخم في فلسطين يعتبر إلى حد كبير تضخماً مستورداً ويظهر حساسية كبيرة تجاه الأسعار العالمية، وبشكل خاص أسعار الغذاء و الوقود (سلطة النقد، تقرير التضخم ،2012)، ويضاف لذإلك تبعية

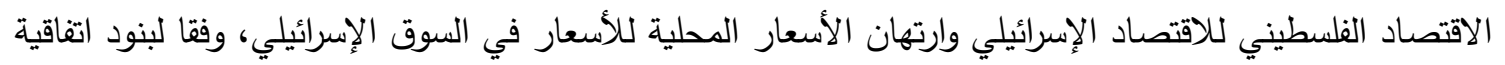
باريس الذي وقعته منظمة التحرير الفلسطينية مع إسرائيل عام 1994م، لذلك كان هناك حاجة كبيرة لبحث مشكلة التضخم في الاقتصاد الفلسطيني ومعرفة أهم المحددات والأسباب الكامنة وراء ارتفاع الأسعار اللسلع والخدمات. مشكلة الدراسة يعتبر الاقتصاد الفلسطيني من الاقتصاديات الناشئة التي تعاني من مجموعة من التحديات والعراقيل التي تقف عائقاً في سبيل تحقيق تنميتها وتطورها، وأحد أهم هذه التحديات هو حالة عدم الاستقرار الاقتصادي والنقدي في ني

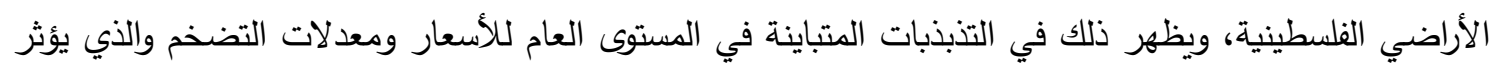
سلباً على مستوى الرفاه الاجتماعي من جهة، ومن جهة أخرى يعمل على ضعف الإنى الاستثار وهروب رؤوس الأموال

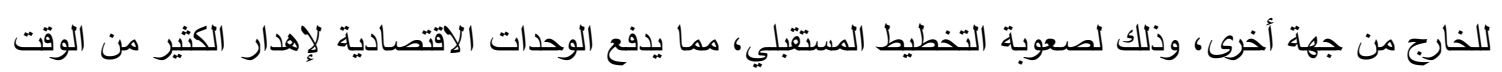

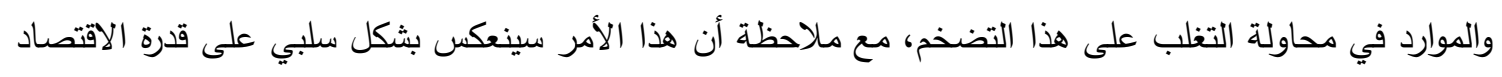
على الإنتاج والنمو بالمعدلات الطبيعية. ورغم مخاطر التضخم المحدقة في الاقتصاد الفلسطيني إلا أنه يتزامن كذلك مع ارتفاع معدلات البطالة واستمرار

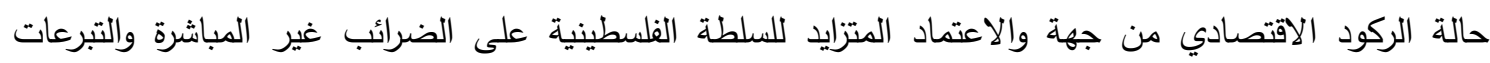

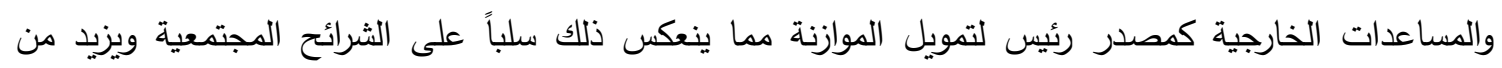
الأعباء الاقتصادية على الأسر الفلسطينية.

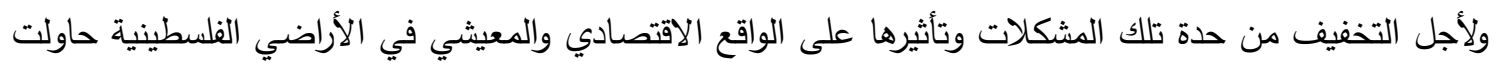
هذه الدراسة البحث في أسباب ومحددات التضخم في الاقتصاد الفلسطيني من خلال الإجابة على التساؤل الرئيس التالي: ماه:

ماهي العوامل الاقتصادية التي تؤثر على معدلات التضخم في الأراضي الفلسطينية خلال الفترة (2000 2014)، وما هي أكثر هذه العوامل تأثيراً? فرضيات الاراسة

يتمثل الفرض الأساسي لهذه الدراسة في أن التغيرات في معدل التضخم في فلسطين تكون نتيجة لعدد من المتغيرات

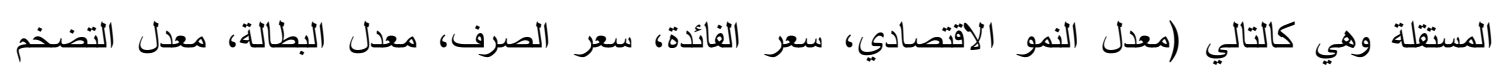
العالمي، معدل التضخم الإسرائيلي، وعليه يمكن صياغة الفرضية الأساسية للدراسة كالآتي: 
يوجد أثر ذو دلالة إحصائية للمتغيرات المستقلة (معل النمو الاقتصادي، معدل الأجور، التسهيلات الأتعانية،

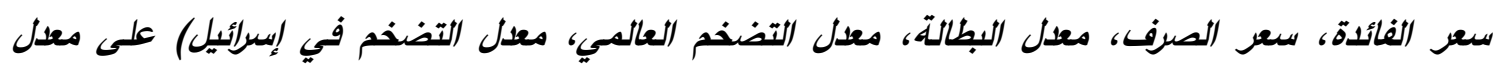
التضخم في فلسطين.

أهداف الدارسة تهدف هذه الدراسة إلى تحقيق ما يلي: 1. حصر العوامل التي تؤثر على التضخم في اقتصاديات العالم وذلك من خلال الاطلاع على الدراسات السابقة ذات العلاقة. 2. تحديد أكثر العوامل تأثيراً على معدل التضخم في الاقتصاد الفلسطيني وذلك باستخدام أساليب الاقتصاد القياسي، وسوف يتم استخدام نموذج قياسي يتوافق مع النظريات المفسرة للتضخم بهدف اختبار مقدرة هذه النظريات على تفسير ظاهرة التضخم في الاقتصاد الفلسطيني. 3. الخروج بمجموعة من التوصيات الملائمة للمساعدة في علاج مشكلة التضخم في الاقتصاد الفلسطيني. أهمية الدراسة العوامل التي تؤثر على التضخم تختلف من دولة إلى أخرى وتتغير هذه العوامل بتغير الزمن وبتغير الأوضاع والظروف الاقتصادية السائدة، بالتالي تكمن أهمية هذه الدراسة في النقاط الآتية: 1. الدراسة توضح أهم العوامل التي تؤثر على معدلات التضخم في فلسطين، حيث أن ذلك سيساعد على اقتراح

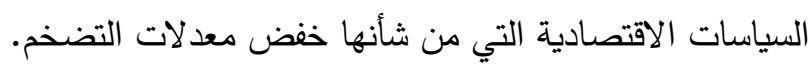

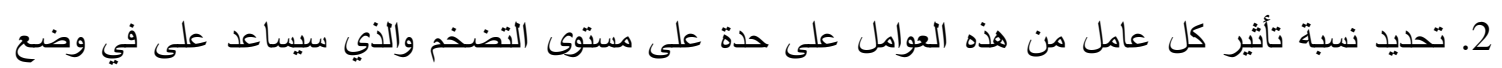
سياسات وحلول لكل عامل من عوامل التضخم. 3. تقدم الدراسة لمتخذي القرار الفلسطيني رؤية ممكن الاستفادة منها في علاج مشكلة التضخم في الأراضي الفلسطينية لكبح جماحه ومعالجته بما يتلاءم ومستويات النمو الاقتصادي.

منهجية الدارسة تحقيقاً لأهداف الدراسة، ولاختبار صحة الفرضيات تم إتباع المنهج الوصفي الكمي لتفسير هذه الظاهرة، ودراسة العلاقة بين المتغير التابع والمتغيرات المستقلة والتحقق من مدى صحتها، حيث تم استخدام بيانات لسلسلة زمنية

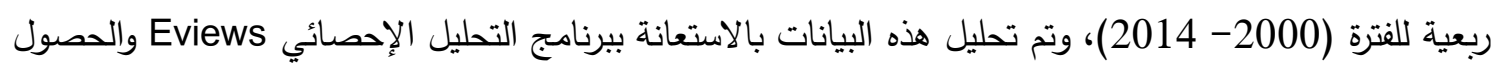
على أفضل النتائج.

مصادر جمع البيانات تم جمع البيانات اللازمة لمتغيرات الدراسة وذلك بالاعتماد على بيانات السلاسل الزمنية للاقتصاد الفلسطيني، والتي

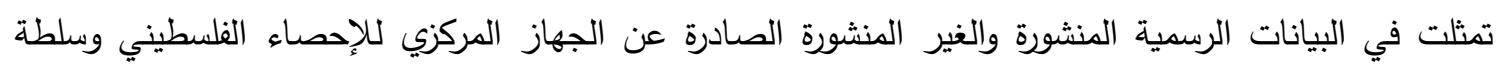

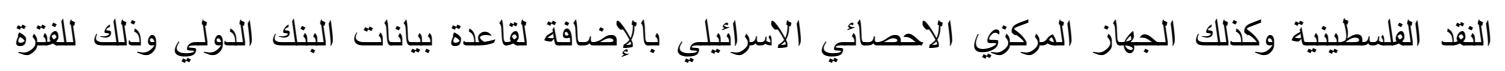
الزمنية من الربع الأول لعام 2000 إلى الربع الرابع لعام 2014م، وذللك حسب الاحبي توافرها. 
حدود الدراسة الحد المكاني: شملت الدراسة الأراضي الفلسطينية المتمثلة في قطاع غزة والضفة الغربية وبدون مدينة القدس

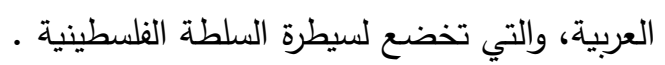
الحد الزمني: غطت الدراسة الفترة الزمنية الواقعة بين عامي لعيه (2000 - 2014).

الإطار النظري والدراسات السابقة: أولاً: نظرية التضخم

عند النظر إلى أدبيات الاقتصاد، يمكن التمييز بين مصدرين رئيسين للتضخم هما العوامل الناشئة من جانب التبات

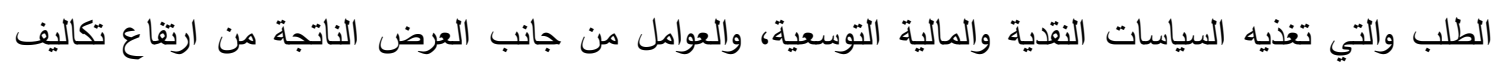

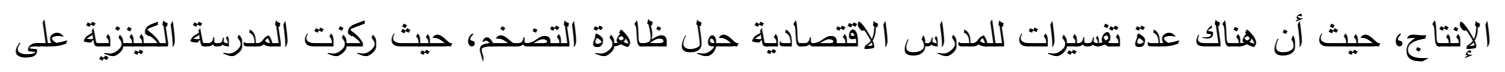
جانب الطلب لتقسير التضخم وأشارت إلى أن سوق العمل يلعب دوراً هاماً في ارتفاع مستوى الأسعار من خلال

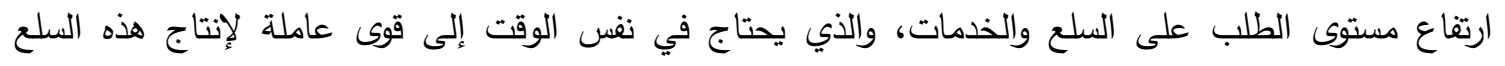

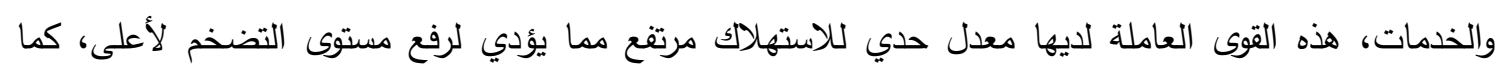

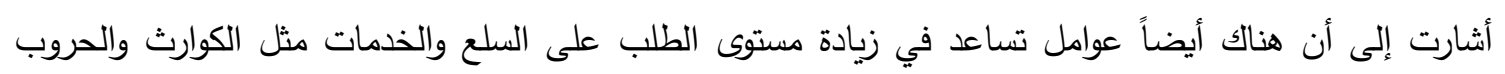

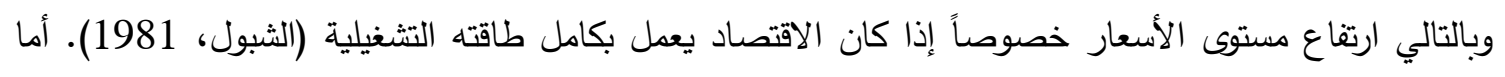
المدرسة النقدية فقد اعتمدت في تفسير ظاهرة التضخم على نظرية كمية النقود، وتثير هذه النظرية إلى أنه في حالة بقاء سرعة دوران النقود وحجم السلع والخدمات ثابت فإن زيادة النقود تؤدي إلى ارتفاع مستوى الأسعار

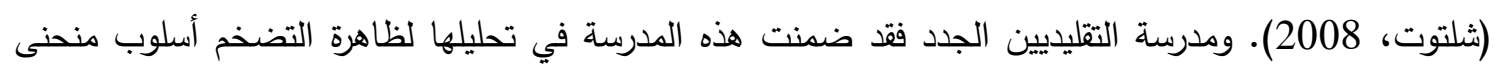
فيليبس، حيث يؤدي انخفاض معدل البطالة إلى زيادة مستوى التضخم والعكس صحيح بحكم أن التضخم دالة

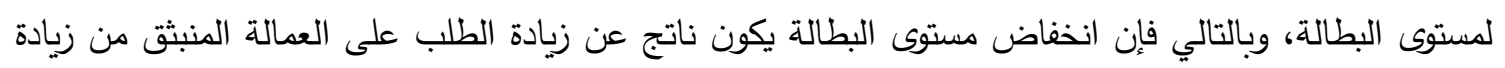

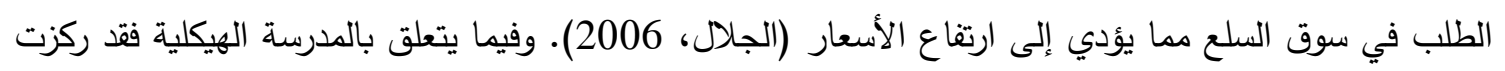

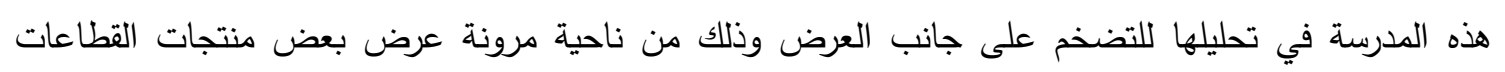

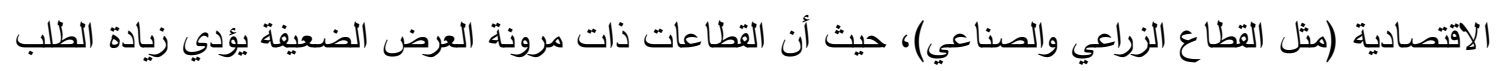

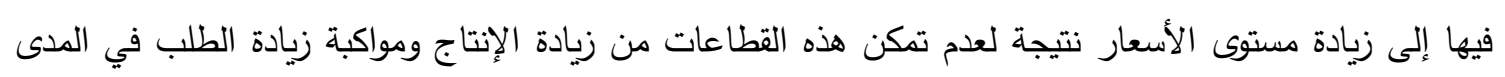
القصير (زكي، 1980).

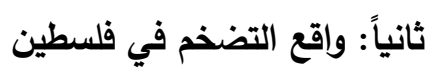
يعبر الرقم القياسي لأسعار المستهلك1 عن مدى التغير في قيمة النقود أي القوة الثرائية بالنسبة للمستهلك، وبالاستعانة بالرقم القياسي لأسعار المستهلك يمكن احتساب معدل التضخم²، حيث أن الارتفاع في المستوى العام

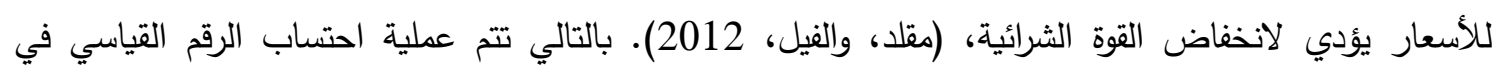

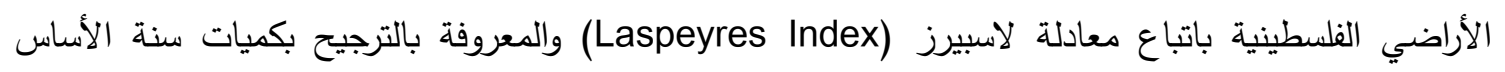

1 يعرف الرقم القياسي لأسعار المستهلك على أنه: وسيلة إحصائية لقياس التغيرات في أسعار السلع والخدمات ضمن سلة المستهلك بين فترة

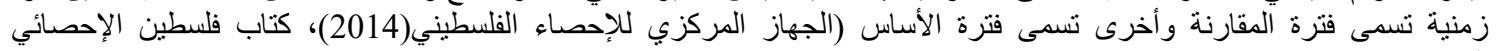

Inflation $={\frac{C P I_{t}-C P I_{(t-1)}}{C P I_{(t-1)}}}^{2}$

حيث أن: CPIt الرقم القياسي لأسعار المستهلك في سنة ما.CPI 
(المناسيب المرجحة)، وحسب هذه الصيغة، يتم حساب الرقم القياسي لكل سلعة (منسوب السعر)، ومن ثم يتم احتساب متوسط المناسيب ويتم ترجيحها بكميات سنة الأساس لكل مجموعة إلى أن نصل إلى حساب الرقم القياسي لتصني

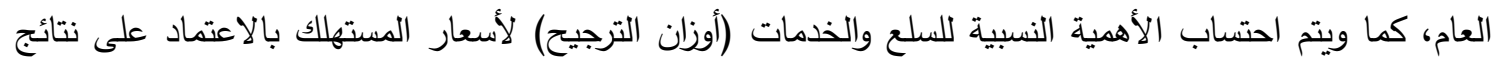

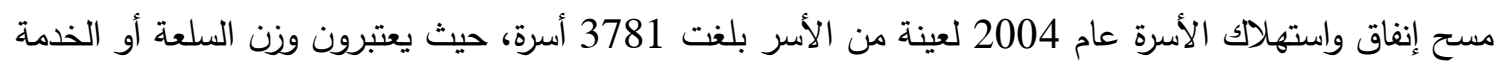
جزءاً من سلة المستهلك، واحتسبها يتم بطريقة نسبية ليمثل جزءاً من مائة ألف وهو حجم سلة المستهلك (الجهاز

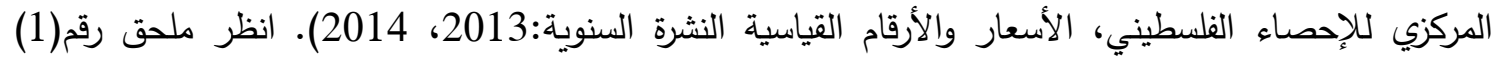

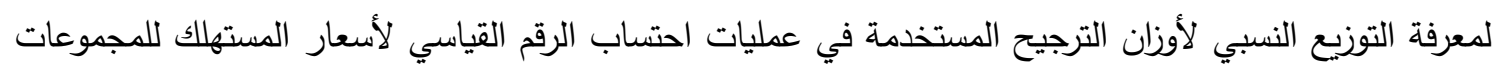

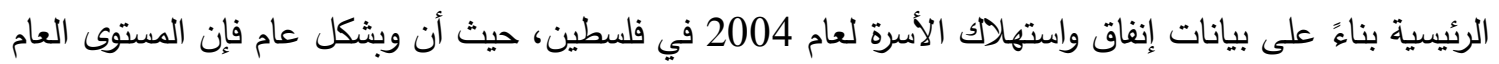

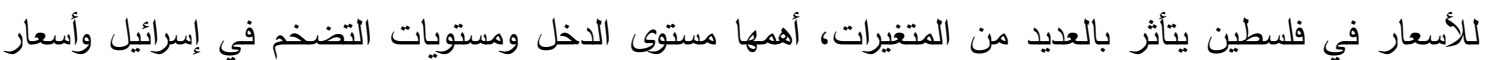

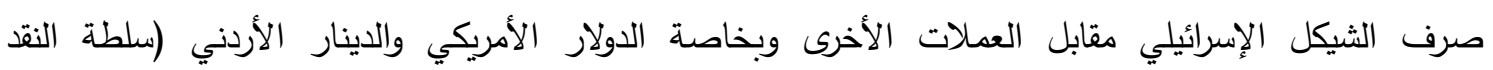
الفلسطينية، 2006). والثكل البياني التالي يوضح معدلات التضخم خلال فترة الدراسة، كما يلي:

شكل رقم (1): معدل التضخم خلال الفترة (2000-2014)

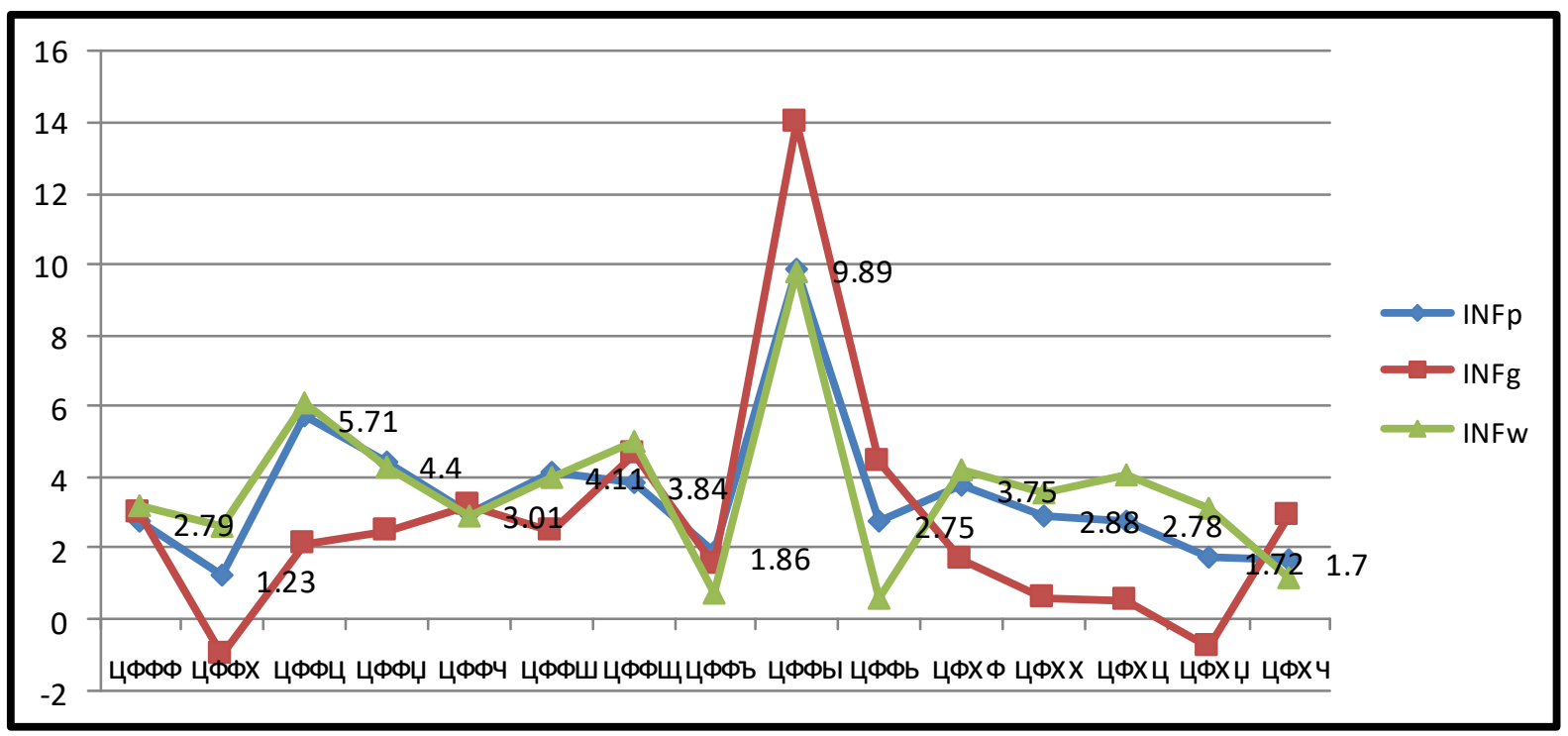

بالاعتماد على بيانات الملحق رقم (2)

ويلاحظ من الثكل (1) أن أدنى مستوى للأسعار في فلسطين (INFp) كان في العام 2001 حيث وصلت لمعدل 1.2\% ويعود ذلك لانخفاض أسعار الواردات عالمياً وانخفاض التضخم في اسرائيل الناجم عن تباطؤ

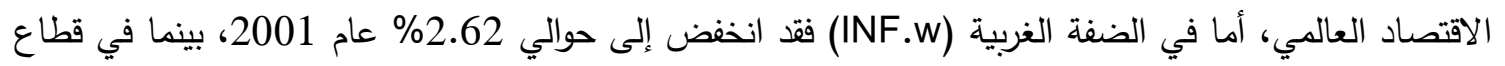

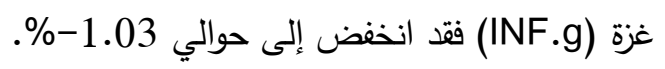
ثم عاد للتذبذب ما بين الارتفاع والانخفاض مرة أخرى لكنه شهد ارتفاعاً ملحوظاً وغير مسبوق عام 2008 بنسبة 89.89\% في فلسطين وبنسبة 9.81\% في الضفة الغربية وبنسبة 13.9\% في قطاع غزة، وذلك على خلفية موجة الغلاء والارتفاع في الأسعار العالمية، وتراجع أداء الاقتصاد الفلسطيني خلال عامي 2006 و 2007 ولغاء وقف المنح والمساعدات الدولية وانقطاع رواتب الموظفين (سلطة النقد الفلسطينية، 2010). 
أما خلال الفترة (2010-2012) فقد بلغ متوسط معدل التضخم في فلسطين 3.13\%، بينما بلغ متوسط معدل التضخم في الضفة الغربية حوالي 3.95\% أما في قطاع غزة فقد بلغ حوالي 0.92\% لنفس الفترة، ويعزى

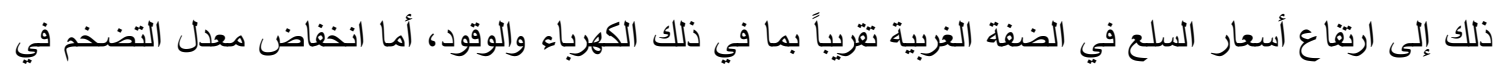

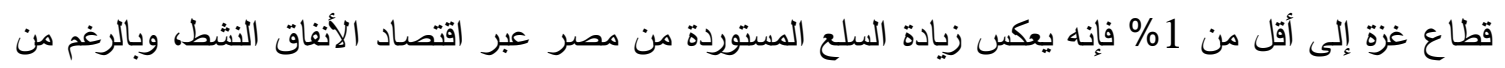

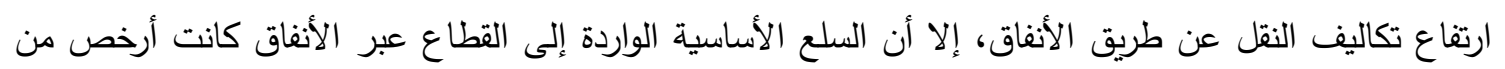

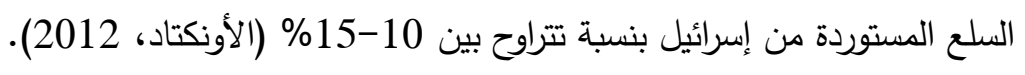
بينما في عام 2013 فقد أظهر تحليل الرقم القياسي لأسعار المستهلك حدوث تراجع ملحوظ في معدلات التضخم حيث بلغ حوالي 1.72\% في فلسطين وحوالي 3.10\% في الضفة الغربية وحوالي 0.77-0.

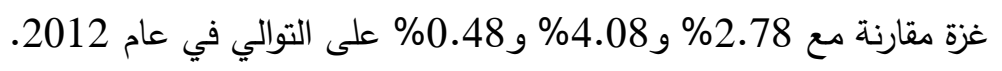

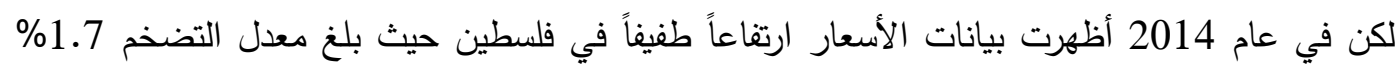
وهي ذات النسبة المتحققة خلال العام 2013 ويمثل هذا التراجع امتداداً للاتجاه التتازلي الذي اتخذته مستويات التضخم خلال السنوات الأخيرة، متأثرة على وجه الخصوص بانخفاض تكاليف الواردات وتراجع الأسعار العالمية

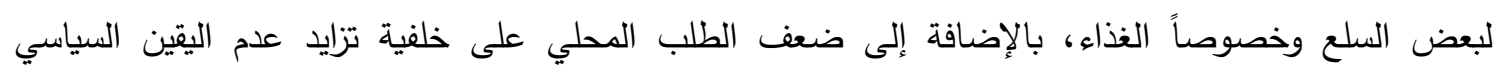

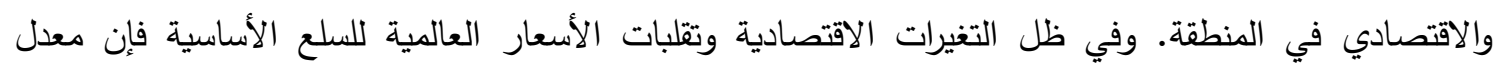

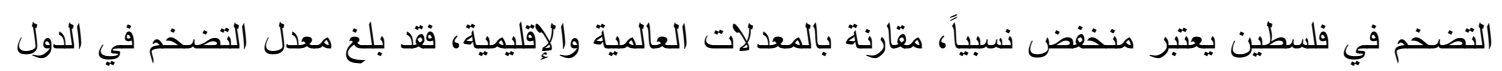

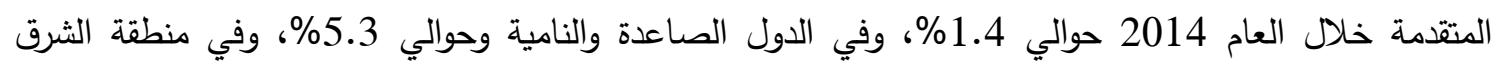

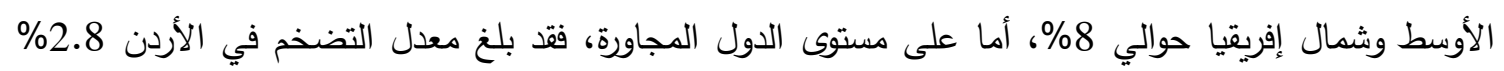
وفي مصر 10.2\% وفي إسرائيل 0.5\% (سلطة النقد الفلسطينية، التقرير السنوي:2013، 2014، 2015). غير أن معدل التضخم المتحقق في فلسطين يخفي الكثير من التناقضات، ففي الوقت الذي تراجع فيه معدل

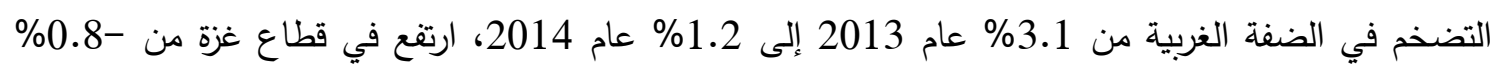
إلى 2.9\%.

ويعكس هذا التفاوت في مستويات التضخم بين الضفة الغربية وقطاع غزة حجم الاختلاف في الظروف

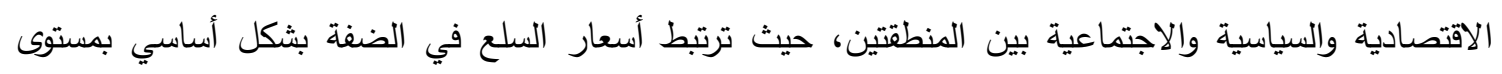

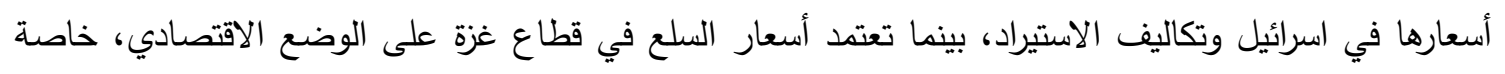

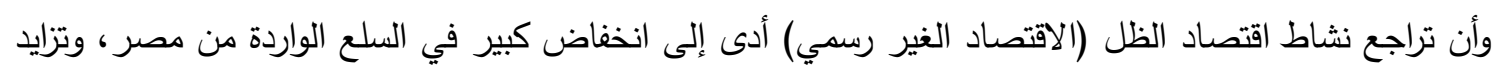

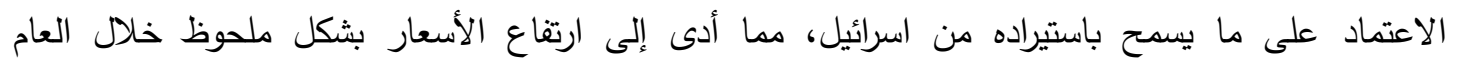
2014(سلطة النقد الفلسطينية، التقرير السنوي:2015).

\section{الدراسات السابقة}

العديد من الدراسات السابقة تطرقت إلى موضوع ارتقاع الأسعار للسلع والخدمات أو التضخم في اقتصاديات الدول، ولقد أولى العلماء موضوع العوامل التي تؤثر على معدلات التضخم (محددات التضخم) أهمية كبرى من بين القضايا الاقتصادية، حيث ظهرت وجهات نظر مختلفة للمدارس والنظريات الاقتصادية والتي ملتي

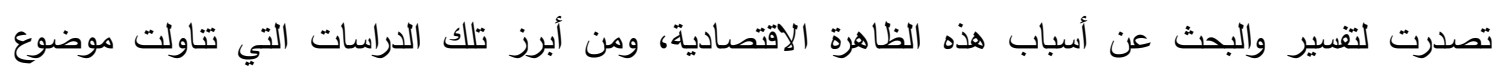
التضخم، ما يلي: 
أولاً: الدراسات العربية: الدراسات العربية التي تتاولت موضوع التضخم في العالم العربي وفلسطين محدودة واقتصرت على استخدام عدد محدود من المتغيرات منها أثر سعر الصرف على المؤشرات الكلية ومن ضمنها التضخم، وأثر السياسة الإنفاقية وسعر الفائدة والناتج المحلي الإجمالي الحقيقي، وهي على على النحو الآتي: 1. شنبيش (2013): "دراسة العلاقة بين التضخم وعرض النقود وسعر الصرف في الاقتصاد الليبي. هدفت هذه الدراسة إلى تحليل ظاهرة التضخم في الاقتصاد الليبي من خلال قياس العلاقة الكمية بين التضخم وبعض المتغيرات الاقتصادية الأخرى خلال الفترة (1992-2008)، من هذه المتغيرات الناتج المحلي الإجمالي الحقيقي، سعر صرف الدينار الليبي مقابل الدولار، عرض النقود، وقد توصلت الاراسة إلى وجود علاقة طردية بين مستوى التضخم وعرض النقود بالمعنى الضيق في الاقتصاد الليبي، وكذلك وجود علاقة طردية بين التضخم وسعر صرف الدينار الليبي، وكذلك توجد علاقة عكسية بين التضخم والناتج المحلي الإجمالي الحقيقي.

2. خضر (2012): "تأثير سعر الصرف على المؤشرات الكلية للاقتصاد الفلسطيني (1994- 2010)".

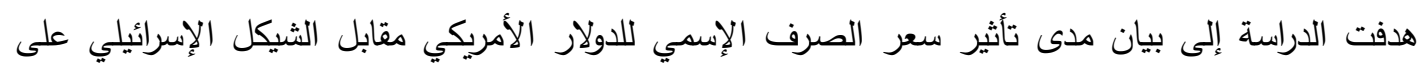

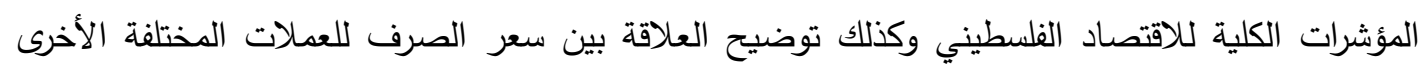
وبين معدل التضخم، استخدمت هذه الدراسة المنهج الوصفي التحليلي وذلك من خلال الاستعانة بطريقة

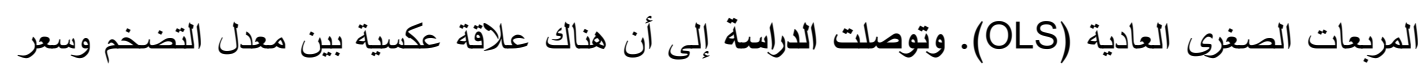
الصرف الإسمي للدولار الأمريكي مقابل الثيكل الإسرائيلي. 1. رجب (2011): "أثر السياسة الإنفاقية على التضخم في فلسطين":

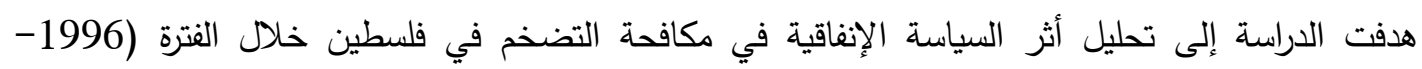

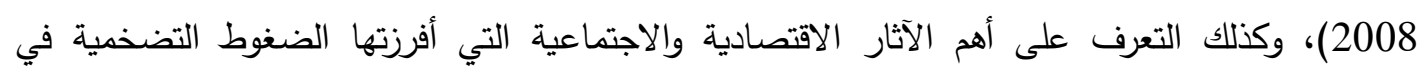
الاقتصاد الفلسطيني، هذا بالإضافة إلى التعرف على حالة التضخم الراهنة في فلسطين. وقد توصلت الاراسة إلى وجود تأثير معنوي للمتغيرات المستقلة (إجمالي النفقات العامة، النفقات الجارية وصافي الإقراض، الألى الأجور

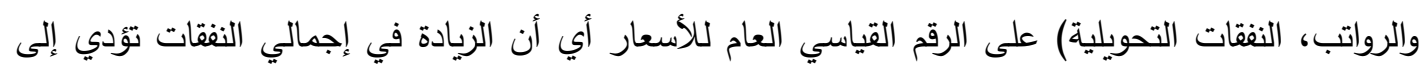

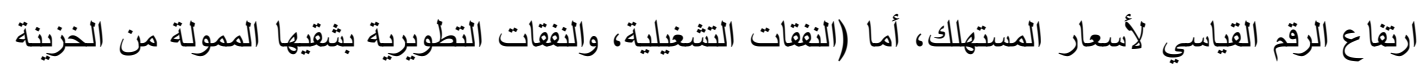
والممولة من المنح والمساعدات) فلم يكن لها أي تأثير على الرقم القياسي لأسعار المستهلك.

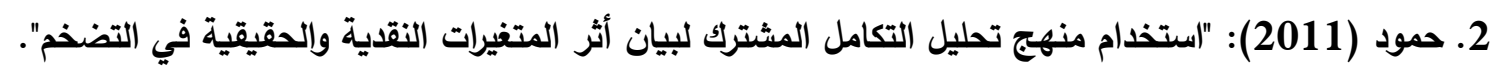
هدفت هذه الدراسة إلى معرفة أثر كل من العرض النقدي، والناتج المحلي الإجمالي، والإنفاق الحكومي،

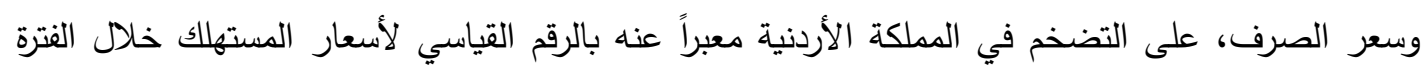

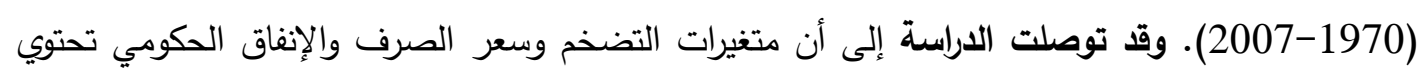
على جذر الوحدة وتصبح مستقرة بعد أخذ الفرق الأول بعكس متغيرات عرض النقد والنيرات والناتج المحلي الإجمالي فهي مستقرة عند المستوى، وكذلك وجود علاقة سببية بين المتغيرات غير المستقرة في المستوى وأن هذه الأه

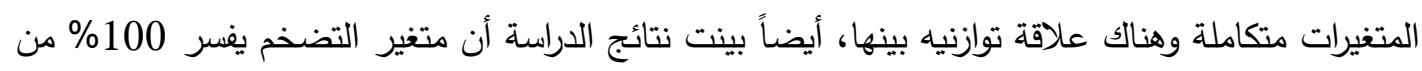
مكونات التباين في الفترة الأولى عند حدوث صدمة بمقدار انحراف معياري واحد في المتغير نفسه. 3. الجراح (2011): "مصادر التضخم في المملكة العربية السعودية: دراسة قياسية باستخدام مدخل اختبارات 
هدفت هذه الدراسة إلى تحليل وتقدير مصادر التضخم في المملكة العربية السعودية خلال الفترة (19702007) وذلك ضمن إطار نموذج العرض والطلب الكلي باستخدام الأساليب القياسية الحديثة، ولأجل ذلك تم تمدئ استخدام عدد من المتغيرات منها معدل نمو الناتج المحلي الحقيقي، الإنفاق الحكومي الرأسمالي كنسبة من الناتج المحلي، معدل نمو النقود بمعناه الواسع، مؤشر الإنتاج الصناعي للدول الصناعية، المؤشر العالمي

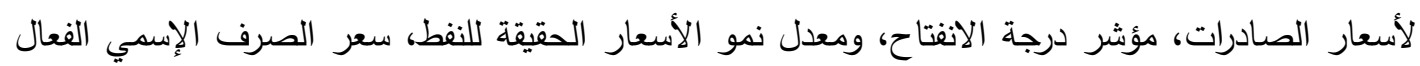

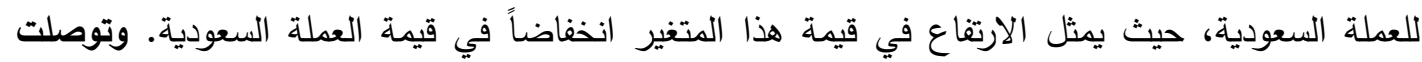
الداسة إلى أن هناك أهمية للعوامل المرتبطة بالعالم الخارجي (مؤشر درجة الانفتاح، والمؤشر العالمي

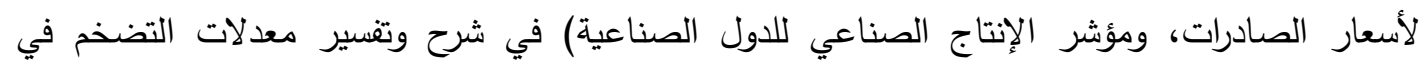

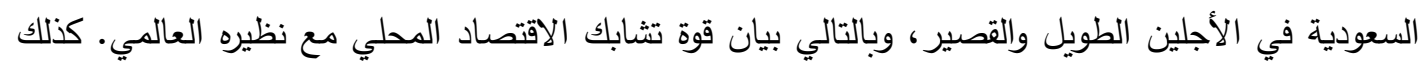

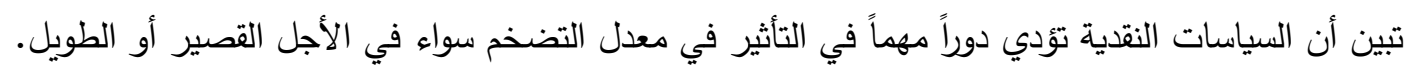
4. إلهيتي وآخرون (2010): "أثر تقلبات أسعار الصرف في معدلات التضخم في الاقتصاد الأردني والتركي".

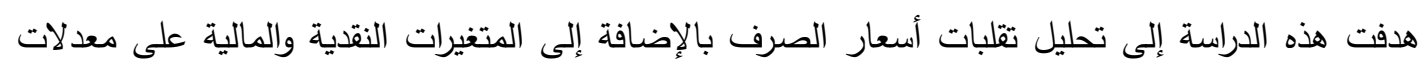
التضخم في الاقتصاد الأردني والتركي خلال الفترة (1980-2002). ومن المتغيرات المستخدمة لبيان أثرها

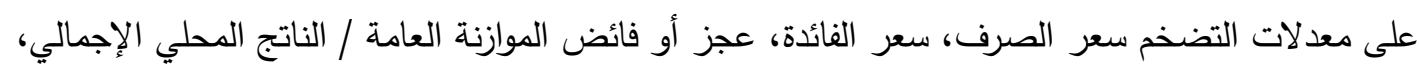

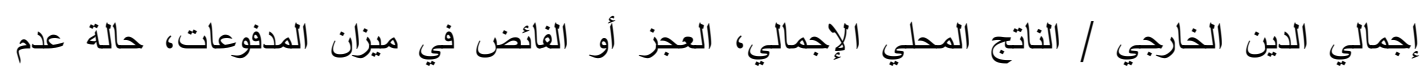

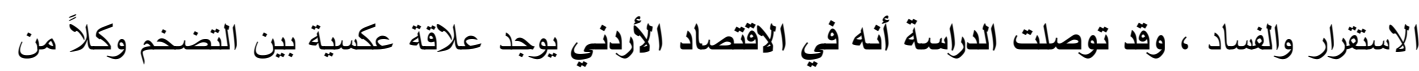

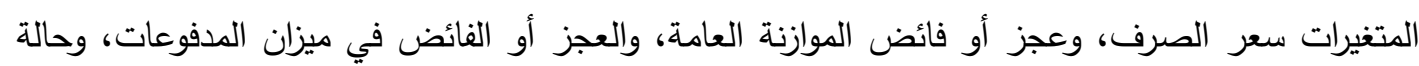

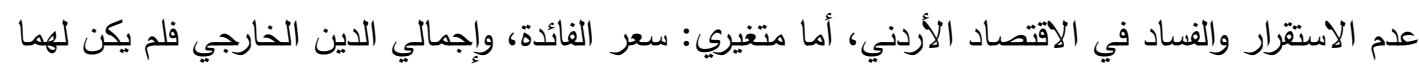
أي تأثير معنوي في التأثير على التضخم بالأردن. أما في حالة الاقتصاد التركي فقد تبين وجود علاقة طادئ طردية بين التضخم وكلاً من سعر الصرف وعجز أو فائض الموازنة العامة، وكذلك وجود علاقة عكسية مع العجز أو الفائض في ميزان المدفوعات، أما باقي المتغيرات فلم يظهر لها معنوية في التأثير على معدلات التضخم بالاقتصاد التركي وذلك لعدم اجتيازها الاختبارات الإحصائية.

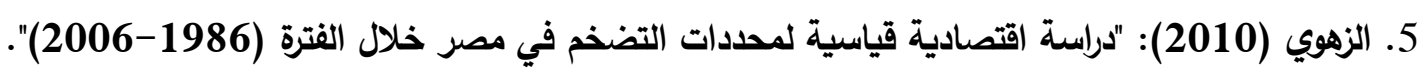
هدفت الدراسة إلى تقدير معاملات دالة محددات التضخم في مصر في الأجلين الطويل والقصير خلال الفترة (1986- 2006)، وقد تم لهذا الغرض استخدام أربعة متغيرات مستقلة وهي: الناتج المحلي الإجمالي الحقيقي، وسعر الصرف، وسعر الفائدة، وعرض النقود كعوامل لها تأثير على سلوك معدل التضخم. وقد

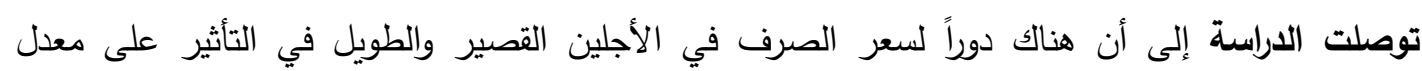
التضخم في مصر كذلك النقود بمعناها الواسع، أما بالنسبة لمتغيري سعر الفيائدة الاسمي والناتج الألين المحلي

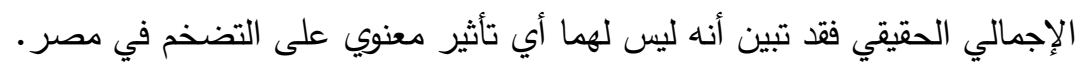
6. الهجهوج (2009): "محددات التضخم في دول مجلس التعاون لدول الخليج العربية: أسلوب التكامل المشترك".

هدفت الدراسة إلى تحديد المتغيرات الاقتصادية المسببة للتضخم في دول مجلس التعاون لدول الخليج العببي خلال الفترة (1980-2007) سواء في المدى القصير أو الطويل وذلك من خلال استخدام أسلوب التكامل المشترك من أجل تقدير النموذج القياسي، وتم استخدام عدد من المتغيرات منها معدل نمو عرض المدي النقود، مستوى سعر الصرف الفعلي الاسمي، معدل التغير في سعر النفط، معدل نمو حجم الائتمان المصرفي نوني 
المتاح للقطاع الخاص، مستوى التضخم العالمي، معدل نمو الطلب الكلي. وتوصلت الدراسة إلى أن التضخم

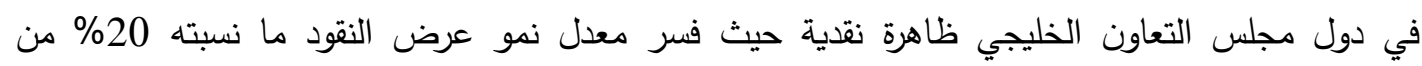
مكونات التضخم في المدى الطويل في حين بلغ تفسير عرض النقود 14\% في المدى القصير ، كذلك فإن التضخم في دول التعاون الخليجي يستجيب وبشكل طردي للمتغيرات الاقتصادية المتمثلة في معدل التغير في في في فئي

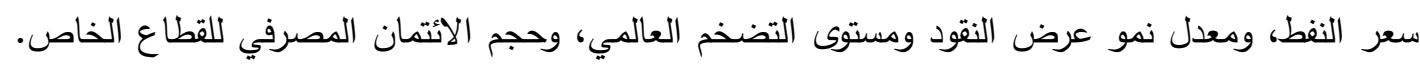
بالإضافة لضعف تفسير معدل سعر الصرف الفعلي الاسمي، ومعدل نمو الطلب الكلي.

7. العمر (2007): "محدات التضخم بدولة الكوبت".

هدفت هذه الدراسة إلى التعرف على العوامل المؤثرة في التضخم المحلي في اقتصاد صغير منفتح على العالم الخارجي ممثلاً بدولة الكويت خلال الفترة (1972-2004)، واعتمدت الدراسة في تفسيرها على ثلاثة متغيرات وهي الرقم القياسي لأسعار الواردات والذي يمثل التضخم المستورد، ورصيد النقد المحلي، والناتج

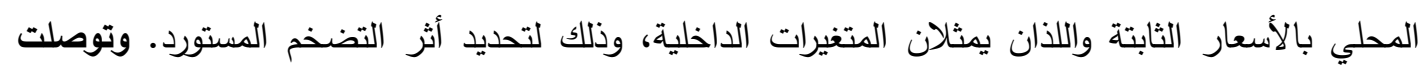

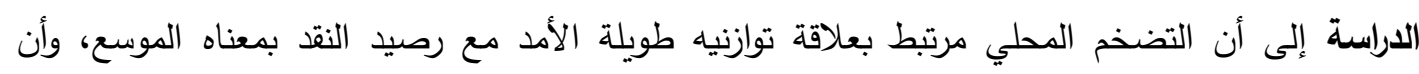
التضخم المحلي يتأثر بالناتج المحلي الحقيقي، في حين تشير النتائج إلى غياب أي تأثير معنوي للتضخم المستورد على التضخم المحلي بالكويت.

8. هتهات (2006): "دراسة اقتصادية وقياسية لظاهرة التضخم في الجزائر". هدفت هذه الدراسة إلى تحليل ظاهرة التضخم في الاقتصاد الجزائري خلال الفترة (1988-2003)، بالإضافة

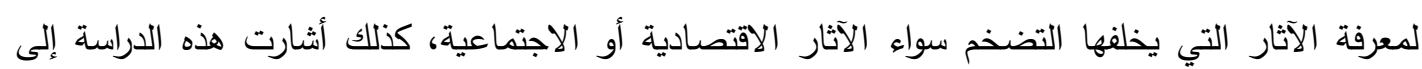

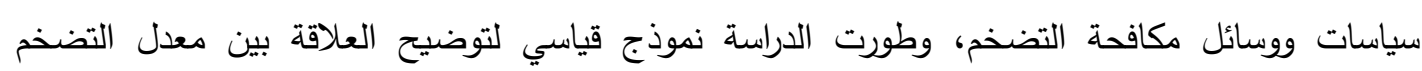

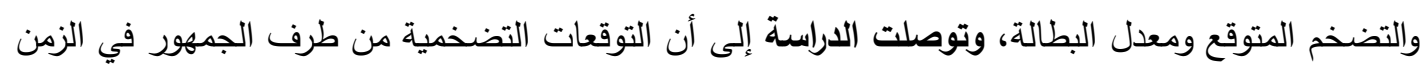
السابق لها أثراً معنوياً في زيادة معدل التضخم، كذلك وجود علاقة عكسية ما بين معدل البطالة ومعدل التضخم ووجود علاقة ثنائية الاتجاه بينهما، بمعنى أن التضخم يسبب البطالة وكذلك البطالة تسبب التضخم.

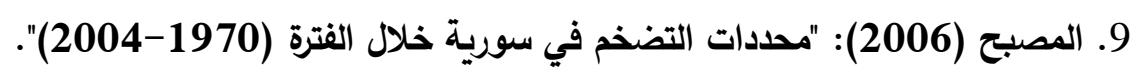

هدفت هذه الدراسة إلى قياس أثر بعض المتغيرات الاقتصادية على التضخم في سورية، لمعرفة محدداته

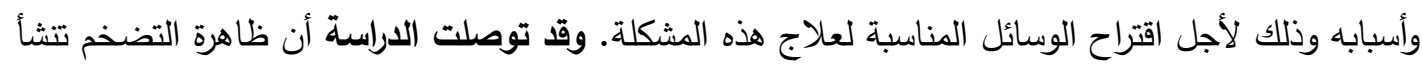

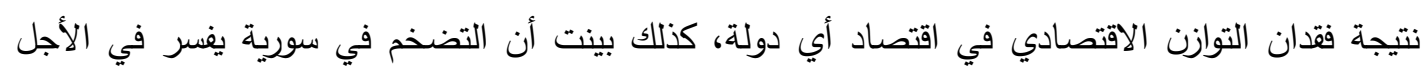

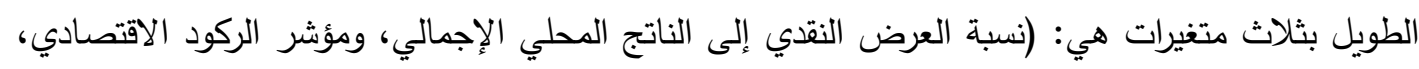

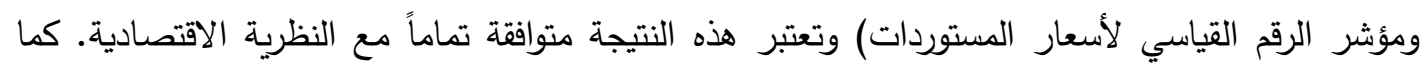

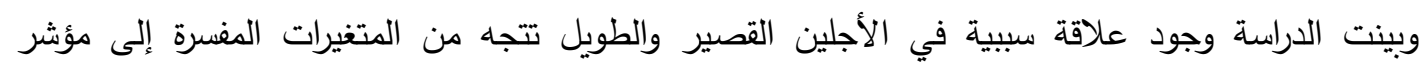
التضخم.

10. الجلال (2006): "دور السياسات النقدية والمالية في مكافحة التضخم في البلدان النامية - دراسة حالة

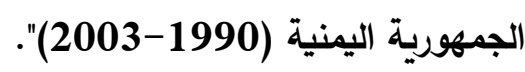

هدفت الدراسة إلى تحديد خصائص الاقتصاد اليمني ودراسة أهم العوامل الداخلية والخارجية والاختلالات الهيكلية التي ساهمت في تغذية الضغوط التضخمية في الاقتصاد اليمني، كذلك اهتمت ببيان أهم الآثار

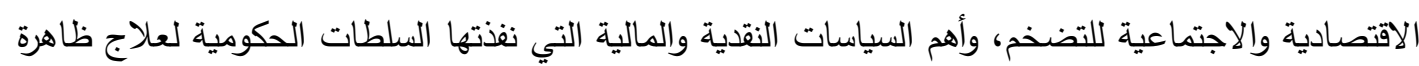


التضخم وتقييم مدى فعالية هذه السياسات، وتوصلت الاراسة إلى أن التضخم في البلدان النامية يرتبط بعدد

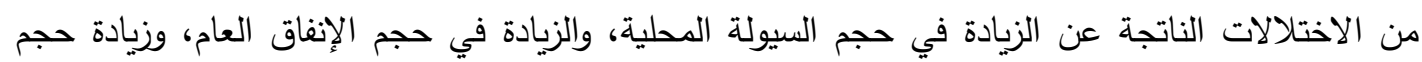
الاستهلاك النهائي الكلي، بالإضافة إلى الدور الذي تمارسه العوامل الخارجية متمثلة في تفاقم حجم المديونية

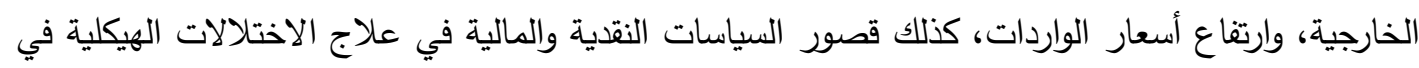
بنيان الاقتصاد الوطني الناجمة عن اختلال علاقة النمو بين قطاعات الاقتصاد الوطني.

ثانياً: الدراسات الأجنبية

1. Sahadudhhen I (2012), A Cointegration and Error Correction Approach to the Determinants of Inflation in India".

هدفت هذه الدراسة إلى التعرف على معدلات التضخم في الاقتصاد الهندي خلال الفترة من الربع الأول من

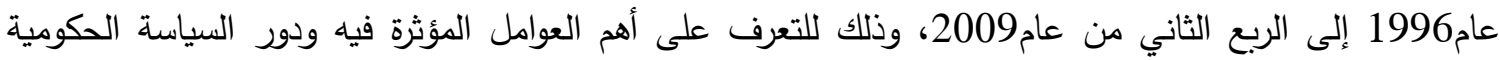
النقدية والمالية في التأثير على معدلات التضخم في الاقتصاد الهندي واحتوت الدراسة على مجموعة من المتغيرات

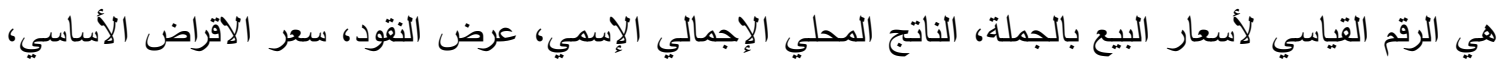

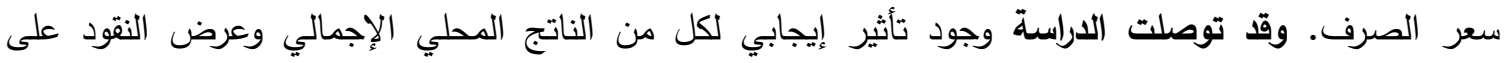
التضخم في المدى الطويل، وأما معدل الفائدة وسعر الصرف فقد كان تأثيرهما سلبي على التضخم في الهند.

2. MarialAwouYol (2010), "Determinants of Inflation in Sudan: An Empircal Analysis".

هدفت هذه الدراسة للتعرف على المحددات الأساسية للتضخم ودراسة اتجاه العلاقة السببية بين المتغيرات في السودان خلال الفترة (1970-2008). واستخدمت مجموعة من المتغيرات منها عرض النقود الاسمي، الناتج

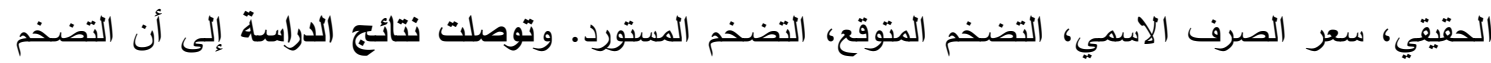

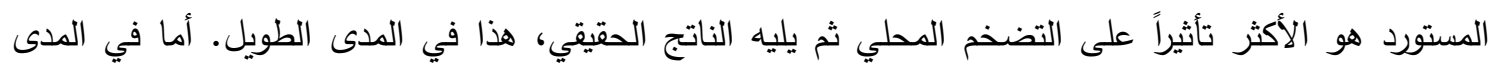
القصير فقد كانت أهم محددات التضخم المحلي في السودان هي سعر الصرف الاستي عي والناتج الحقيقي والتضخم المستورد، حيث كانت تحمل نفس الاشارات المتوقعة. أما اختبار السببية فقد أشار لوجود علاقة ثنائية الاتجاه بين التضخم وكلاً من سعر الصرف وعرض النقود، بينما كانت أحادية الاتجاه مع المتغيرات الأخرى.

3. Kevin Greenidge \& Dianna DaCosta (2009), "Determinants of Inflation in Selected Caribbean Countries".

هدفت هذه الدراسة إلى التعرف على واقع التضخم وأهم محددات التضخم الرئيسية في مجموعة من دول البحر الكاريبي وهي: جامايكا، وغويانا، وباربادوس، وترينيداد وتوباغو، وذلك باستخدام بيانات سلسلة زمنية سنوية للفترة

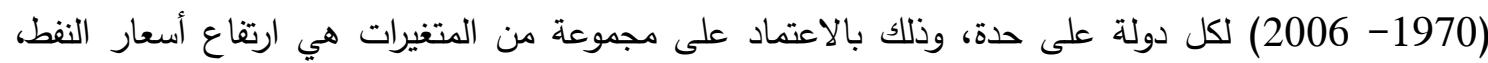

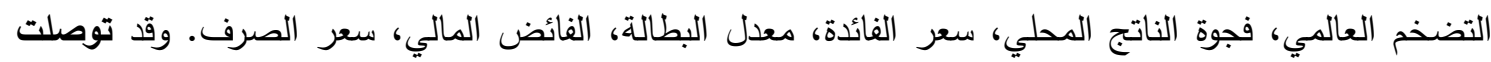
الاراسة فيما يتعلق بدولة باربادوس، يوجد علاقة طردية بين التضخم وكلاً من ارتفاع أسعار النفط ومعدل البطالة

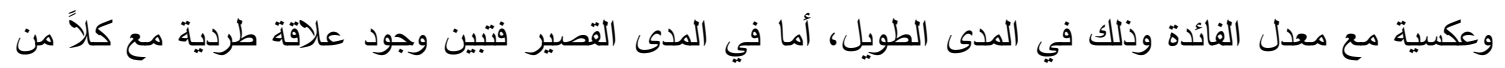

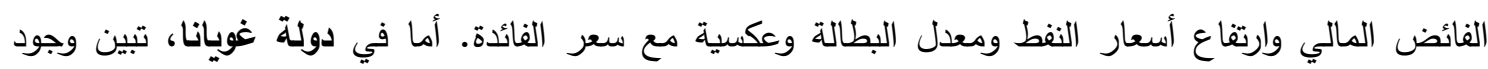

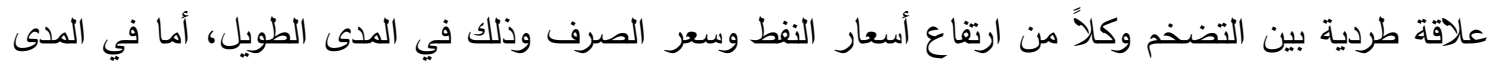
القصير فتبين وجود علاقة طردية مع كلاً من ارتفاع أسعار النفط وسعر الصرف وعكسية مع سعر الفائدة وفجوة 
الناتج المحلي. وأما في دولة جامايكا، تبين وجود علاقة طردية بين التضخم وكلاً من ارتفاع أسعار النفط ومعدل الفائدة وذلك في المدى الطويل، أما في المدى القصير فتبين وجود علاقة طردية مع كلاً من ارتفاع أسعار النفط وفجوة الناتج المحلي وسعر الصرف والفائض المالي وعكسية مع سعر الفائدة. وفي دولة ترينيداد وتوباغو، تبين وجود علاقة طردية بين التضخم وكلاً من ارتفاع أسعار النفط وسعر الصرف وذلك في المدى الطويل، أما في في

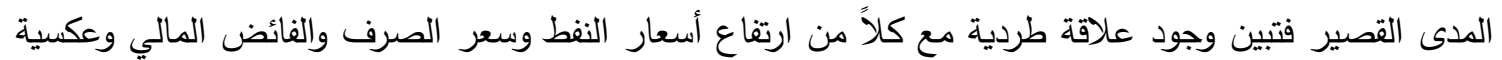

4. Mohammad Rahimi \& Mosayeb Pahlavani (2009), "Sources of Inflation in Iran: مع فجوة الناتج المحلي. Application of the ARDL Approach".

هدفت الدراسة إلى التعرف على أهم المصادر الرئيسية للتضخم في إيران وذلك باستخدام بيانات سلاسل زمنية سنوية للفترة (1971- 2006) وذلك مع مراعاة خصوصية الاقتصاد الإيراني خلال هذه الفترة باستخدام المتغيرات الاقتصادية التالية (عرض النقود، سعر الصرف، الدخل الحقيقي، التضخم المتوقع، التضخم المستورد، متغير وهمي يمثل الحرب العراقية الايرانية(1980-1988)) • وتوصلت الدراسة أنه في المدى الطويل يوجد علاقة طردية بين التضخم وكلاً من عرض النقود، وسعر الصرف، والتضخم المستورد، ومعدل التضخم المتوقع، وكذلك مع المتغير الوهمي، وفي مقابل ذلك كانت العلاقة عكسية مع الدخل الحقيقي. أما في المدى القصير فكانت النتائج مشابهة لما كانت عليه في المدى الطويل.

5. AbdulAleem Khan \& Others (2007), "Determinants of Recent Inflation in Pakistan".

هدفت الدراسة إلى التعرف على أهم مسببات ومحددات التضخم في الباكستان خلال الفترة (1972-2006). حيث استخدمت مجموعة من المتغيرات وهي اقتراض القطاع الحكومي، إجمالي الناتج القومي الحقيقي، الطلب الحقيقي،

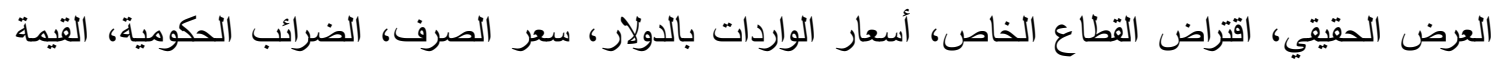

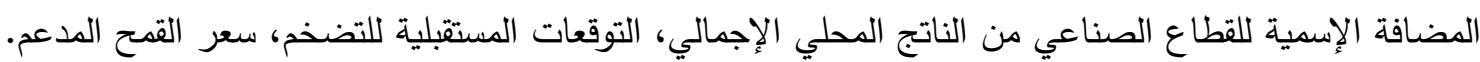

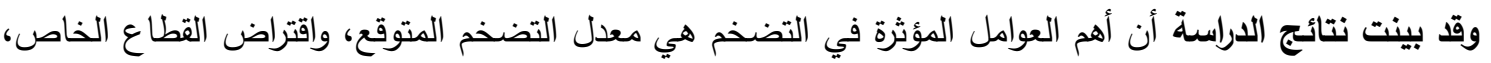

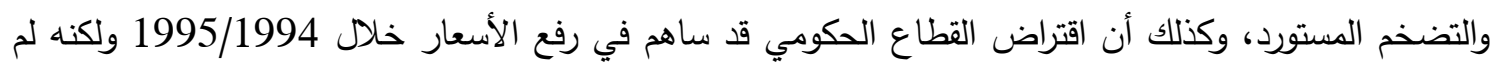

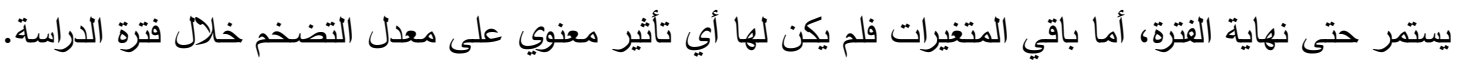

6. Byung-YeonKim (2001), "Determinants of Inflation in Poland: A Structural Cointegration Approach".

هدفت هذه الدراسة إلى تحليل محددات التضخم في الاقتصاد البولندي خلال الفترة من (1990- 1999)، وذلك باستخدام بيانات ربع سنوية لمجموعة من المتغيرات وهي (اللوغاريتم الطبيعي لسعر صرف الزلوتي (Zloty)

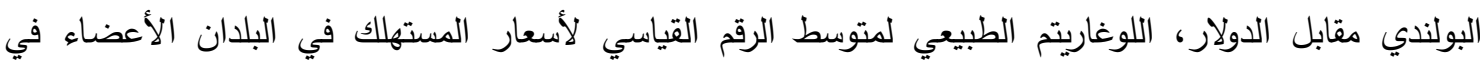
الاتحاد الأوروبي، اللوغاريتم الطبيعي للإنتاج الصناعي في بولندا، اللوغاريتم الطبيعي لمعدل الأجور الاسمية لإنية الثهرية في بولندا، اللوغاريتم الطبيعي لعرض النقود الاسهي بمعناه الواسع في بولندا). وقد بينت نتائج الدراسة

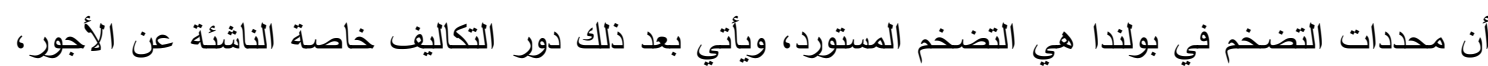

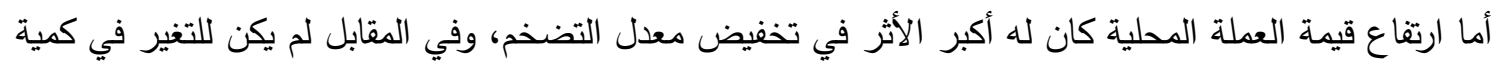
النقود المعروضة أي تأثير على التضخم في بولند. وبالتالي فإن قطاع العمل والقطاع الخارجي كان لهما أكبر

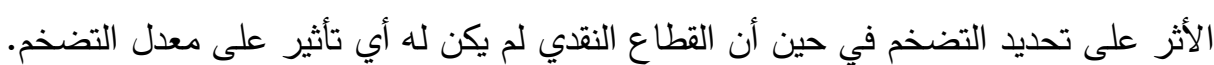

7. Samuel A. Laryea \& Ussif R. Sumaila (2001), "Determinants of Inflation in Tanzania". 


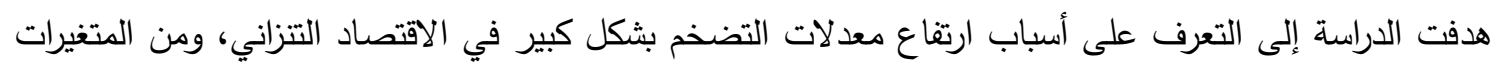

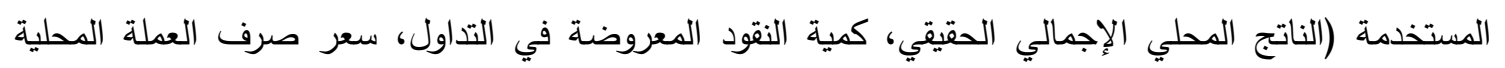
مقابل الدولار) • وقد توصلت الاراسة إلى وجود علاقة طردية بين التضخم وكمية النقود المعروضة للتداول، وكذلك أثارت أيضاً إلى وجود علاقة طردية تربط سعر الصرف بالتضخم، بمعنى أن ارتفاع سعر الدولار يؤدي لزيادة

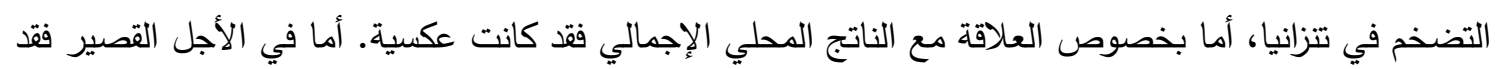
بينت نتائج الدراسة معنوية كل من عرض النقود والناتج المحلي كمحددات للتضخم وعدم معنوية سعر الصرف في الإني

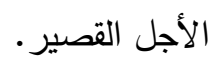

8. Fatukasi Bayo (Without Date), "Determinants of Inflation in Nigeria: An Empirical Analysis".

هدفت الدراسة إلى التعرف على واقع التضخم في الاقتصاد النيجيري بالإضافة لتحليل أسباب الاتجاهات التضخمية التي أصابت الاقتصاد النيجيري خلال الفترة (1981-2003) والسياسات الحكومية المختلفة لعلاج التضخم في المدى الطويل من أجل المحافظة على المستوى المعيشي للمواطنين النيجيزيين. وذلك باستخدام

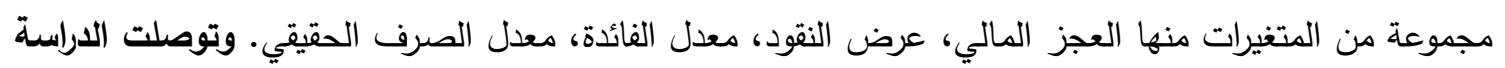
إلى أن المتغيرات التفسيرية في النموذج المقدر تفر ما نسبته 64.2 \% من التغير الحاصل في التضخم في

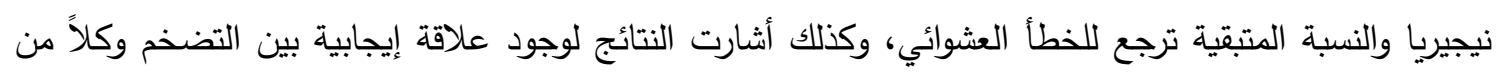
العجز المالي وعرض النقود ومعدل الفائدة، وفي مقابل ذلك كانت العلاقة عكسية مع سعر الصرف.

ثالثاً: التعقيب على الدراسات السابقة من خلال العرض السابق للدراسات التي تتاولت موضوع محددات التضخم في اقتصاديات الدول المختلفة

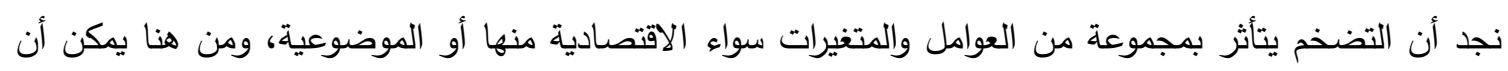

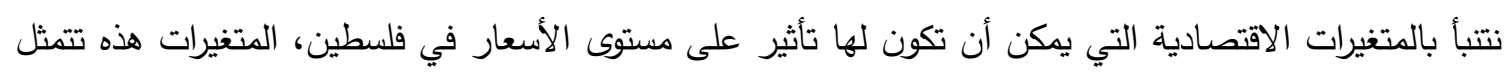

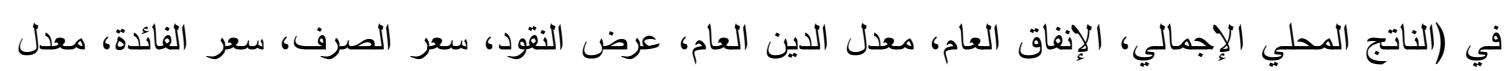

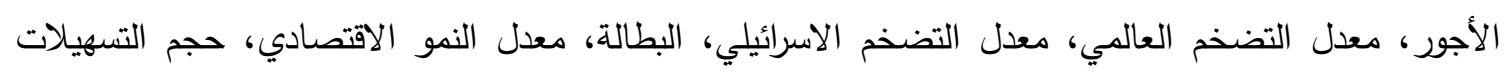
المنوحة)، ولكن لخصوصية الاقتصاد الفلسطيني كونه يعاني من عدم وجود عملة وطنية وتتم معاملاته الاقتصادية بالثيكل الإسرائيلي تم استبدال متغير عرض النقد بالتسهيلات الممنوحة لكل من غزة والضفة، كذلك متغيري الدين العام والانفاق العام لم تتوفر لهما بيانات بشكل منفصل لكل من غزة والضفة وبالتالي تم استبعادهما.

الإطار العملي للاراسة

أولاً: متغيرات الاراسة والنموذج القياسي للاراسة

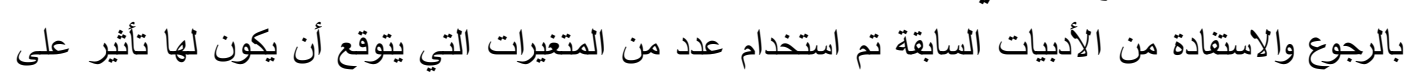

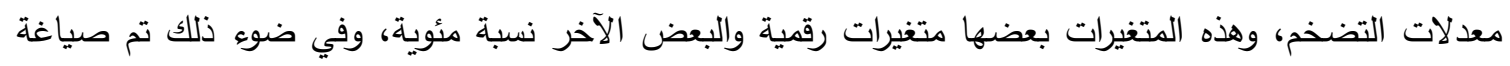

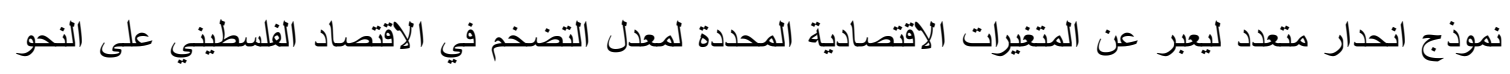
INF = f (GR، INT، EXR، UNR، INF IS، INF التالي: حيث أن: 
المتغير التابع: معدل التضخم (Inflation Rate) : وهو الارتفاع المستمر والملموس في المستوى العام للأسعار، ويتم قياسه من خلال التغير في الرقم القياسي لأسعار المستهلك CPI (سامويلسون، وآخرون، 2001)، ويرمز لـأله

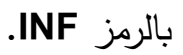
المتغيرات المستقلة، وهي كالآتي: 1.النمو الاقتصادي Economic Growth: وتم التعبير عنه بنصيب الفرد من الناتج الاجمالي في نموذج الضفة الغربية ويقاس بإجمالي الناتج المحلي مقسوماً على عدد السكان (سامويلسون، 2006)، أما في قطاع غزة فتم

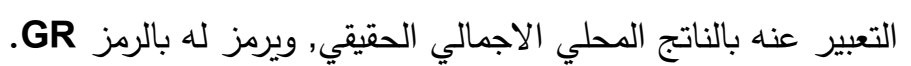
2. معدل الفائدة (Interest Rate) كنسبة مئوية: وهو الثمن المدفوع نظير استعمال النقود أو الزيادة مقابل إقراض باض

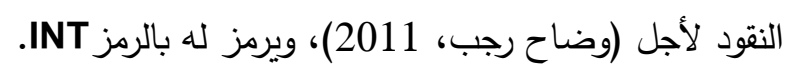
3.سعر الصرف (Exchange Rate): يُعرف سعر الصرف بأنه سعر وحدة من عملة أجنبية معبراً عنها بوحدات

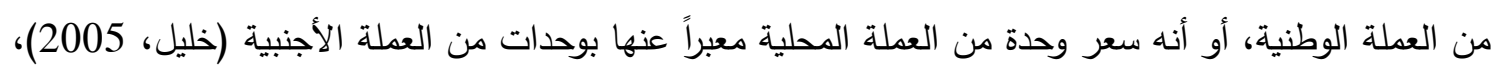

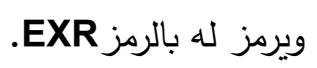
4. معدل البطالة (Unemployment Rate) كنسبة مئوية: حيث تثمل هذه الفئة جميع الأفراد الذين ينتمون لسن

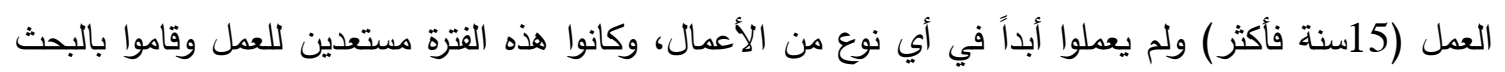

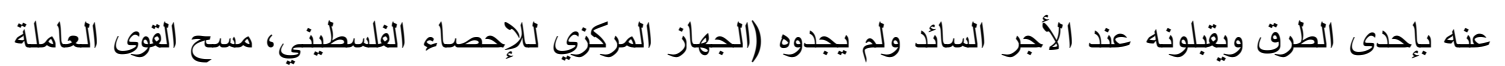

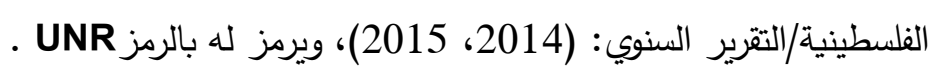
5. معدل التضخم في اسرائيل: ويعرف بأنه الرقم الذي يعكس التغير في مستوى أسعار السلع والخدمات التي تقوم

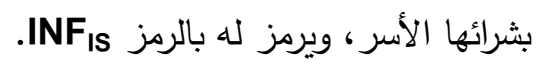

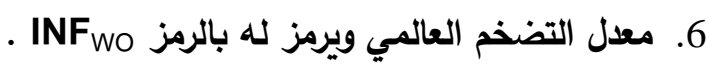

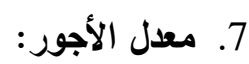

8. التسهيلات الائتمانية: نظراً لعدم وجود عملة وطنية وبالتالي عدم وجود بيانات عن عرض النقد لفترة الدراسة فقد تم

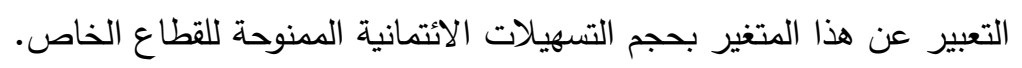

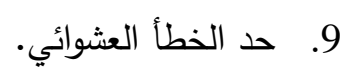

ثانياً: المنهجية الإحصائية والقياسية لتحليل البيانات لقد اتبعت هذه الدراسة المنهج الإحصائي الوصفي لوصف متغيرات الأراسة، والمنهج الكمي القياسي لتحديد العلاقة بين المتغيرات المستقلة والمتغير التابع محل الدراسة بهدف الحصول على معاملات خط الانحدار للمتغيرات المستقلة، حيث تم الاستعانة بمجموعة من الطرق والأساليب الإحصائية والقياسية، والتي تمثلت فيما يلي: لئي: 1. طريقة المربعات الصغرى العادية (OLS): وتعتبر هذه الطريقة من أشهر الطرق التي تستخدم في تقدير

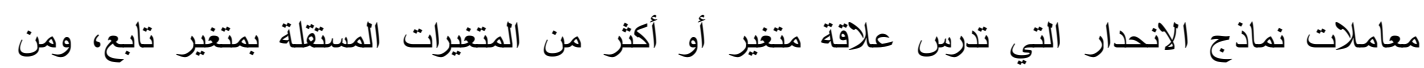

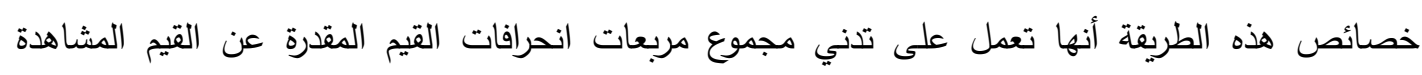
للمتغير التابع (عطية، 2005). كما أنها تمتاز بدقة تقدير المعلمات بعد تحقق افتراضاتها لكي يتم الحكم

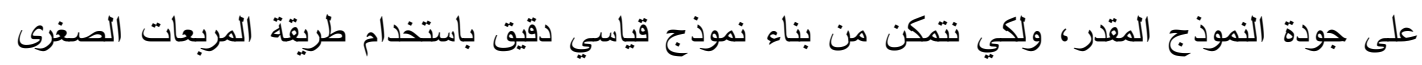

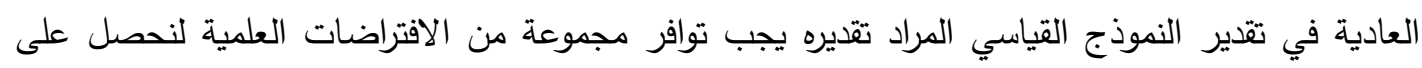


الدقة المطلوبة للنموذج، والتي تتمثل فيما يلي كما يوضحها كلاً من (صافي، 2015) وGujarati، :(2004

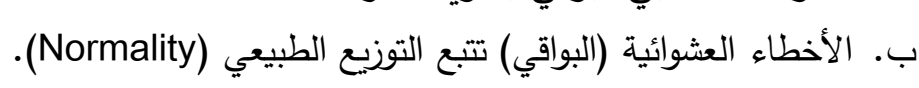

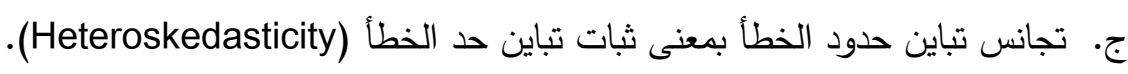
د. استقلال حدود الخطأ بمعنى عدم وجود ارتباط ذاتي في حدود الخطأ (Autocorrelation).

هـ ــ عدم وجود تداخل خطي متعدد بين المتغيرات المستقلة (Multicollinearity). و. المتغيرات المستقلة غير مرتبطة مع حد الخطأ العشوائي.

2. اختبار السكون: يعتبر شرط السكون شرطاً أساسياً لدراسة تحليل السلاسل الزمنية للوصول إلى نتائج سليمة

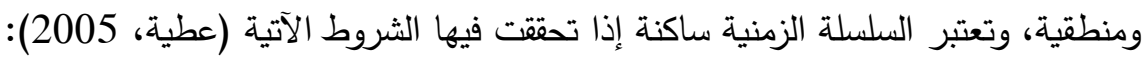

$$
\text { ب. أ. ثبات المتوسط الحسابي للقيم عبر الزمن. }
$$

ج. التغاير بين أي قيمتين لنفس المتغير معتمداً على الفجوة الزمنية بين القيمتين وليس على القيمة الفعلية

$$
\text { للزمن الذي يجب عنده التغاير . }
$$

وهناك العديد من الاختبارات والطرق الإحصائية المستخدمة في الكثف عن سكون السلاسل الزمنية، ونذكر من هذه الاختبارات: اختبار ديكي فولار الموسع (Augmented Dickey Fuller - ADF) وكذلك اختبار فيلبس برون (Philips Perron - PP)، وتعتبر هذه الاختبارات الأكثر استخداماً في مجال الدراسات الاقتصادية والقياسية للكثف عن سكون السلاسل الزمنية.

3. اختبار التكامل المشترك (Cointegration Test): يعرف التكامل المشترك بأنه تصاحب (Association) بين سلسلتين زمنيتين xt): أو أكثر، بحيث تؤدي التقلبات في إحداهما لإلغاء التقلبات في الأخرى بطريقة تجعل بانهل

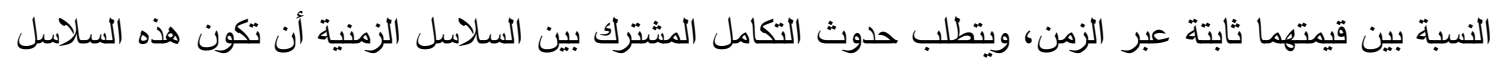

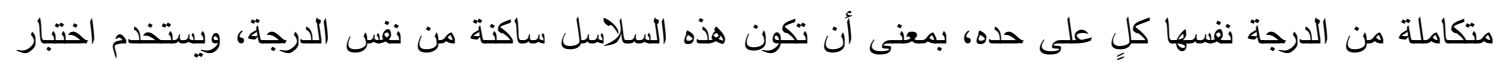

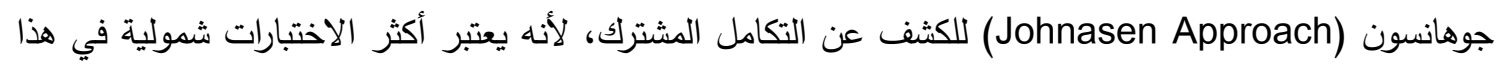

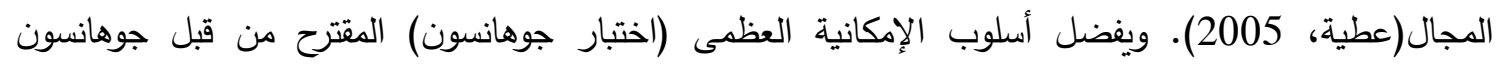
وجوسيلس عام 1990م، عندما يزيد عدد المتغيرات محل الدراسة عن متغيرين لاحتمال وجود أكثر من متجها للتكامل المشترك، ولتحديد عدد متجهات التكامل المشترك اقترح جوهانسون وجوسيلس إجراء اختبارين: الأول اختبار الأثر(Trace) والثاني اختبار القيمة الذاتية العظمى (Maximum) حيث أن كلاهما يعطي نفس النتيجة

(عبد القادر، 2007).

4. النماذج القياسية والإثارات المتوقعة للمعاملات: وبذلك تصبح الصيغة النهائية للنماذج المراد تقديرها كما يلي: أ) نموذج الضفة الغربية:

$$
I N F_{w e}=\beta_{0}+\beta_{1} G R+\beta_{2} I N T+\beta_{3} E X R+\beta_{4} U N R+\beta_{5} I N F_{I S}+\beta_{6} I N F_{w o}+\varepsilon_{t}
$$

حيث أن: 
الإشارات المتوقعة للنموذج هي:

\begin{tabular}{|l|l|l|l|l|l|}
\hline$\beta_{1}>0$ & $\beta_{2}<0$ & $\beta_{3}<0$ & $\beta_{4}<0$ & $\beta_{5}>0$ & $\beta_{6}>0$ \\
\hline
\end{tabular}

م: مo

年

عt

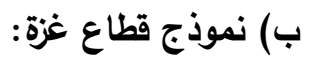

$I N F_{g a}=\alpha_{0}+\alpha_{1} G R+\alpha_{2} I N T+\alpha_{3} E X R+\alpha_{4} U N R+\alpha_{5} I N F_{I S}+\alpha_{6} I N F_{W o}+\varepsilon_{t}$

حيث أن:

الإشارات المتوقعة للنموذج هي:

\begin{tabular}{|l|l|l|l|l|l|}
$\alpha_{1}>0$ & $\alpha_{2}<0$ & $\alpha_{3}<0$ & $\alpha_{4}<0$ & $\alpha_{5}>0$ & $\alpha_{6}>0$ \\
\hline
\end{tabular}

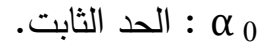

年 عt

ثالثاً: التحليل والتقدير القياسي لنماذج الاراسة

تتاول البحث نتائج الأساليب القياسية المستخدمة في تقدير النماذج القياسية للدراسة، وذلك لكل من اختبارات

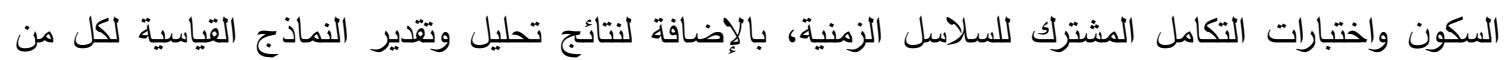

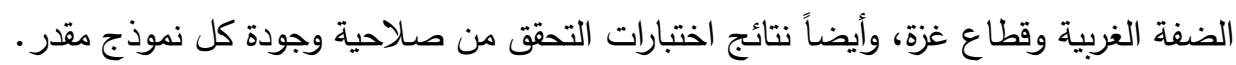

1- نتائج اختبار سكون السلاسل الزمنية: كما سبق توضيحه فإن من شروط تحليل السلاسل الزمنية اختبار

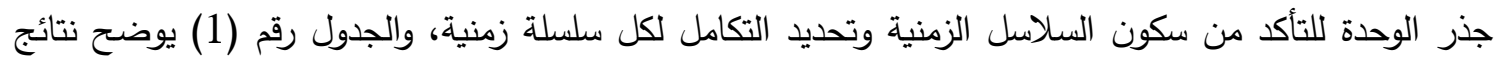

اختبارات جذر الوحدة لجميع متغيرات الدراسة باستخدام اختبار (Philips Perron - PP).

جدول رقم (1): نتائج اختبار الوحدة (Unit Root Test) لمتغيرات الدراسة

\begin{tabular}{|c|c|c|c|c|c|c|c|c|}
\hline \multirow{3}{*}{ Variables } & \multicolumn{8}{|c|}{ Phillips Perron Test } \\
\hline & \multicolumn{4}{|c|}{ الضفة الغربية } & \multicolumn{4}{|c|}{ قطاع غزة } \\
\hline & Level & P-values & $\begin{array}{c}\text { 1st } \\
\text { Difference }\end{array}$ & P-values & $\begin{array}{c}\text { Leve } \\
\text { l }\end{array}$ & P-values & $\begin{array}{c}\text { 1st } \\
\text { Difference }\end{array}$ & P-values \\
\hline INF & -5.56 & $0.0000 *$ & $\ldots$ & $\ldots$ & -6.07 & $0.0000 *$ & $\ldots$ & $\ldots$ \\
\hline GR & -8.72 & $0.0000 *$ & & & -9.76 & $0.0000 *$ & & \\
\hline INT & -2.23 & 0.1979 & $\begin{array}{l}-7.83 \\
\end{array}$ & $0.0000 *$ & -2.23 & 0.1979 & -7.83 & $0.0000 *$ \\
\hline EXR & -1.37 & 0.5889 & -5.56 & $0.0000 *$ & -1.37 & 0.5889 & -5.56 & $0.0000 *$ \\
\hline UNR & -4.10 & $0.0020 *$ & & & -3.57 & $0.0091 *$ & & $\ldots$ \\
\hline INFIS & -5.10 & $0.0001 *$ & $\ldots$. & $\ldots$. & -5.10 & $0.0001 *$ & $\ldots$. & $\ldots$ \\
\hline INFwo & -9.41 & $0.0000 *$ & $\ldots$ & $\ldots$ & -9.41 & $0.0000 *$ & $\ldots$ & $\ldots$ \\
\hline
\end{tabular}

\% 5 رف عدم سكون المتغير عند مستوى ". 
ويتضح من خلال الجدول (1) أن نتائج اختبار جذر الوحدة (Unit Root) لكافة متغيرات الدراسة تبين أنها كانت ساكنة في صورتها الأصلية عند المستوى (Level) باستثناء متغيري معدل الفائدة (INT) وسعر الصرف (EXR)

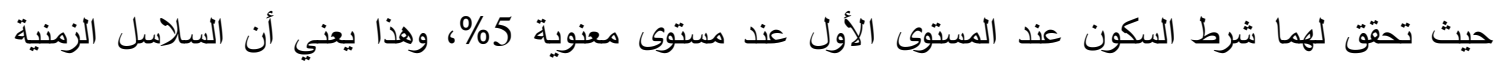

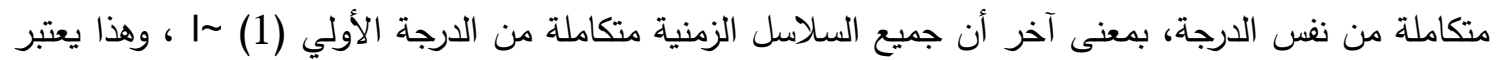
مؤشر جيد لفاعلية استخدام اختبار التكامل المشترك بين السلاسل الزمنية.

2- نتائج اختبار التكامل المشترك: بعد التحقق من الشرط الأول، وهو سكون السلاسل الزمنية، وتحديد درجة تكامل كل سلسة زمنية على حده، والتأكد من أن جميع السلاسل الزمنية متكاملة من نفس الدرجة، تم إجراء التبار التبار جوهانسون للتكامل المشترك للتحقق من وجود علاقة تكاملية طويلة الأجل بين المتغيرات السابقة، ومن أجل تحديد

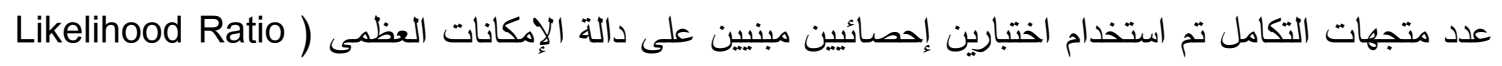
Maximum Eigenvalues وهما اختبار الأثر تtrace) Trace test) واختبار القيم الميزة العظىى (Test (Dmax) Test)، حيث أن كلا الاختبارين يعطي نفس النتيجة، حيث تم إجراء اختبار التكامل الششترك وفق الفرضيات التالية:

الفرضية الصفرية (H=0 - والفرضية البديلة (H > لمتجهات السلسلة. جدول رقم (2): نتائج اختبار التكامل المشترك بطريقة جوهانسون لمتغيرات النموذج المتعدد

\begin{tabular}{|c|c|c|c|c|c|c|}
\hline Hypothesized & \multicolumn{3}{|c|}{ الضفة الغربية } & \multicolumn{3}{|c|}{ قطاع غزة } \\
\hline & \multirow{2}{*}{$\begin{array}{c}\text { Trace } \\
\text { Statistic }\end{array}$} & Critical Value & \multirow[b]{2}{*}{ Prob. } & \multirow[b]{2}{*}{$\begin{array}{c}\text { Trace } \\
\text { Statistic }\end{array}$} & Critical Value & \multirow[b]{2}{*}{ Prob. } \\
\hline & & $\begin{array}{c}\text { Sig Level = } \\
0.05\end{array}$ & & & $\begin{array}{c}\text { Sig Level }= \\
0.05\end{array}$ & \\
\hline None & 144.32 & 47.85 & $0.0000 *$ & 115.32 & 47.85 & $0.000 *$ \\
\hline At most 1 & 84.69 & 29.79 & $0.0000^{*}$ & 65.65 & 29.79 & $0.000^{*}$ \\
\hline At most 2 & 45.72 & 15.49 & $0.0000 *$ & 33.27 & 15.49 & $0.000^{*}$ \\
\hline At most 3 & 17.49 & 3.84 & $0.0001^{*}$ & 16.23 & 3.84 & $0.001^{*}$ \\
\hline
\end{tabular}

* تثير لرفض الفرضية الصفرية عند مستوى 5.84\%.

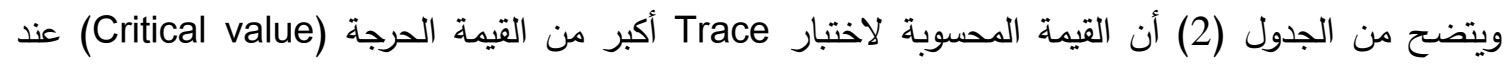
جميع المستويات، لذلك فإننا نرفض الفرضية الصفرية ونقبل الفرضية البديلة، وبالتالي نستتنج أنه يوجد تكامل

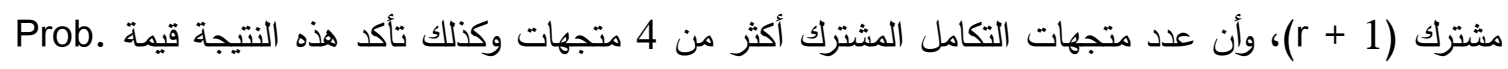
عند جميع المستويات لأنها أقل من 5\%، وهكذا يتضح وجود علاقة توازنية طويلة الأجل بين المتغيرات. 3- نتائج تحليل وتقدير النماذج القياسية: بعد التحقق من سكون السلاسل الزمنية ووجود علاقات تكامل مشترك طويلة الأجل بين المتغيرات، تم تقدير النماذج القياسية حيث تم إجراء تقدير أولي للنموذج القياسي بإدخال

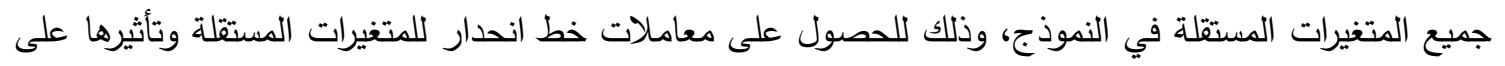
المتغير التابع، حيث أشارت النتائج إلى أن عدد من المتغيرات غير دالة إحصائياً وتتمثل في كل من (التسهيلات

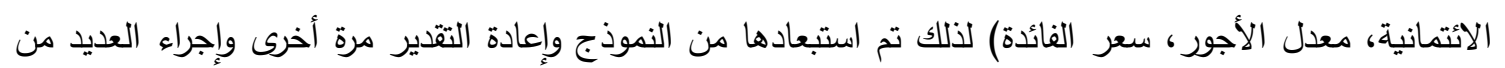
محاولات التقدير للوصول لأفضل نموذج قياسي لمحددات التضخم في الاقتصاد الفلسطيني، وبعد ذلك استقر رأي

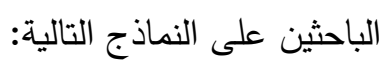


أولاً: نموذج الضفة الغربية: بعد اجراء العديد من المحاولات للوصول لأفضل نموذج قياسي تم تقدير النموذج التالي وذلك بعد التأكد من صلاحية النموذج المقدر والتحقق من شروط طريقة المربعات الصغرى التي سيتم توضيحها وجودة النموذج بشكل عام، فكانت النتائج كما يلي: جدول رقم (3): نتائج تقدير النموذج القياسي للضفة الغربية

\begin{tabular}{|c|c|c|c|c|}
\hline \multicolumn{5}{|c|}{ Dependent Variable: INF } \\
\hline Variable & Coefficient & Std. Error & t-Statistic & Prob. \\
\hline C & 0.565183 & 0.138505 & 4.080593 & 0.0001 \\
\hline INFIS & 0.628108 & 0.157375 & 3.991166 & 0.0002 \\
\hline GR & -0.008131 & 0.002391 & -3.400923 & 0.0013 \\
\hline EXR & -2.127054 & 0.894032 & -2.379169 & 0.0208 \\
\hline \multicolumn{6}{|l}{} \\
\hline
\end{tabular}

بحيث يصبح النموذج القياسي للضفة الغربية على الثكل التالي: $I N F_{w e}=0.565-0.0081 G R-2.1 E X R+0.62 I N F_{I S}+\varepsilon_{t}$

ويبين الجدول رقم (3) أن قيمة معامل التحديد المعدل بلغت (Adj. R2 Re0.25) وهذه القيمة تثير إلى أن المتغيرات المستقلة في النموذج المقدر تفسر ما نسبته 25\% من التغير الحاصل في معدل التضخم في الضفة الغربية، أما النسبة المتبقية فهي ترجع إلى عوامل أخرى. وكذلك نلاحظ أن قيمة الاختبار F بلغت (7.4) بقيمة احتمالية (Prob.=0.000) وهي أقل من (0.05)، وهذا يعني أن هناك علاقة بين المتغيرات المستقلة معاً على المتغير التابع وهذا يعني أن النموذج المقدر جيد ويداليه ويمكن

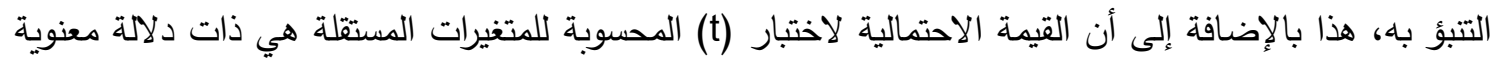
لأنها أقل من 5\%، لذلك جميع المتغيرات المستقلة الداخلة في النموذج المقدر هي دالة إحصائياً. وفي ظل الاعتماد على طريقة المربعات الصغرى العادية، واستخدامها في تقدير نموذج الدراسة، فذلك يشترط إجراء بعض الاختبارات الهامة للتحقق من شروط طريقة التقدير المستخدمة، وذلك بهدف التحقق من صلاحية وجودة النموذج المقدر لكي يتم الاعتماد على نتائج التقدير، وللتحقق من شروط طريقة طرئة المربعات الصغرى تم إجراء

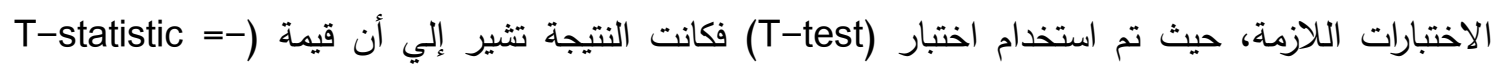
6.94E-16) وأن قيمة الاحتمال (P-Value = 1.000) وتثير هذه النتيجة لعدم رفض الفرضية الصفرية التي تفترض أن المتوسط الحسابي للبواقي تساوي صفر، وهذا يدلل على أن المتوسط الحسابي للبواقي يساوي صغرة .

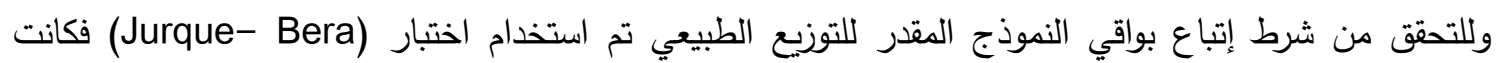
النتيجة تشير أن قيمة الاختبار تساوي (J-B = 1.04) باحتمال بلغ (P-Value = 0.593)، وهذا يبين قبول الفرض العدمي الذي ينص على أن بواقي النموذج المقدر تتبع التوزيع الطبيعي. وكذلك تم استخدام اختبار (White) للتحقق من شرط تجانس تباين حدود الخطأ فكانت النتائج تشير إلى أن قيمة الاختبار تبلغ (4.61) (N*R-squared= على تجانس تباين حدود الخطأ. وأيضاً للتحقق من عدم وجود مشكلة ارتباط ذاتي في حدود الخطأ للنموذج المقدر

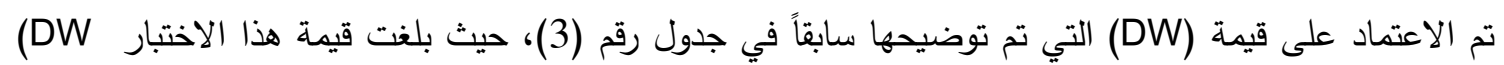
(1.55) وتظهر هذه القيمة أن النموذج خالي من مشكلة الارتباط الذاتي، وذلك لأنها تجاوزت الحد الأعلى للقيمة الجدولية (du = 1.52) وبالتالي خلو النموذج المقدر من هذه المشكلة. أما فيما يتعلق بشرط استقلال المتغيرات 
Variance Inflation ) المستقلة (عدم وجود تداخل خطي متعدد) تم الاعتماد على قيمة معامل تضخم التباين (Factors - VIF حيث أنه كلما زادت قيمة معامل التضخم زادت حدة المشكلة، وعادة ما ينظر لقيم معامل التضخم التي تفوق الرقم 5 على أنها انعكاس لحدة المشكلة (Studenmund, without date)، وقد تم حساب معامل التضخم لمتغيرات النموذج كما هو موضح في الجدول رقم (4)، حيث تثير النتائج إلى أن قيمة (5IF > (5) وذلك لجميع المتغيرات، وهذا مؤشر واضح على خلو النموذج من مشكلة الازدواج الخطي، مما يدل على جودة النموذج المقدر .

جدول رقم(4): نتائج حساب معامل تضخم التباين (VIF)

\begin{tabular}{|c|c|}
\hline Variable & VIF \\
\hline INF IS $_{\text {IS }}$ & 1.14 \\
\hline GR & 1.13 \\
\hline EXR & 1.07 \\
\hline
\end{tabular}

ومن خلال ما سبق نلاحظ تحقيق النموذج المقدر لجميع شروط طريقة المربعات الصغرى العادية، وهذا دليل

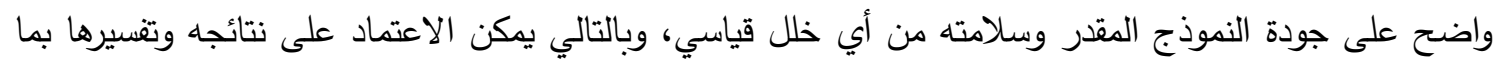
يتناسب مع الواقع الاقتصادي.

اختبار الفرضيات والتفسير الاقتصادي لنموذج الضفة الغربية الفرضية الأولى: وجود علاقة طردية بين معدل التضخم في اسرائيل ومعدل التضخم في الضفة الغربية

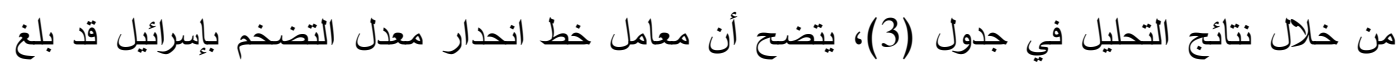

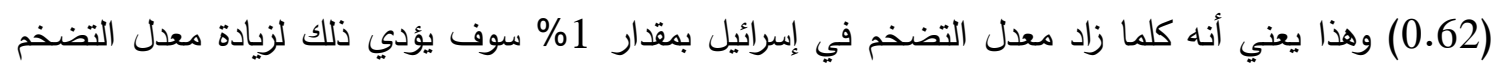
بالضفة الغربية بمقدار 0.62 في حال ثبات المتغيرات المستقلة الأخرى، وهذا يتفق مع فرضية الدراسة ويوافق بونق

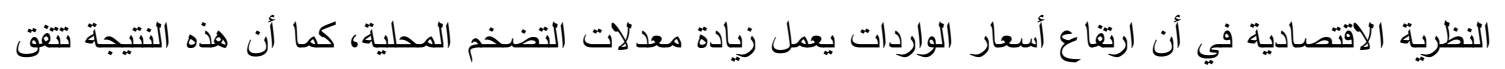

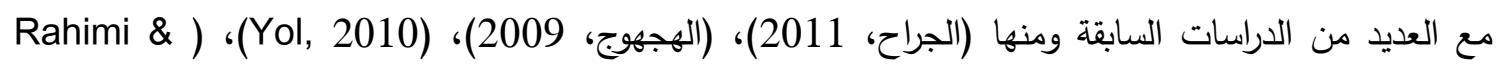

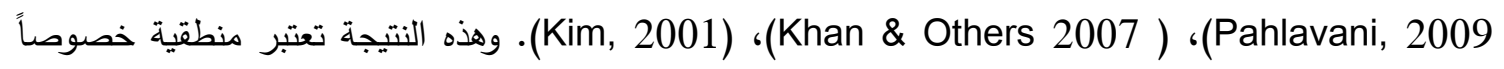
في اقتصاد مكافئ للاقتصاد الفلسطيني، وهذا يفسره تبعية الاقتصاد الفلسطيني للاقتصاد الاسرائيلي مما جعله اقتصاد مستورد للتضخم والأسعار في السوق الفلسطيني مرهونة للأسعار في السوق الاسرائيلي حيث تثير البيانات

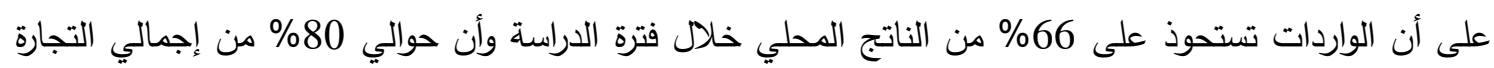
الخارجية الفلسطينية تتم مع الاحتلال الإسرائيلي.

الفرضية الثانية: وجود علاقة طردية بين معدل النمو الاقتصادي ومعدل التضخم في الضفة الغربية

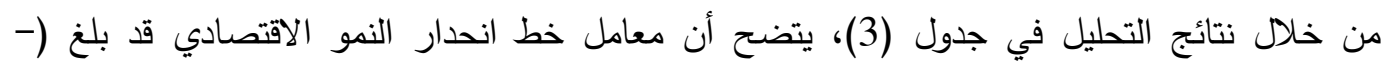

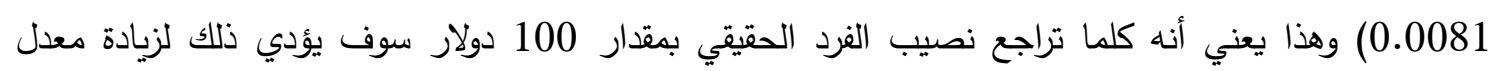
التضخم بمقدار 0.8\% وحدة في حال ثبات المتغيرات المستقلة الأخرى وتختلف هذه النتيجة مع النظرية الاقتصادية في أن زيادة معدل النمو يعمل على زيادة الطلب الاستهلاكي الخاص على السلع والخدمات و بالتالي 
ارتفاع معدل التضخم، وكذلك تتفق هذه النتيجة مع العديد من الدراسات السابقة منها: (شنيش، 2013)، (الجراح،

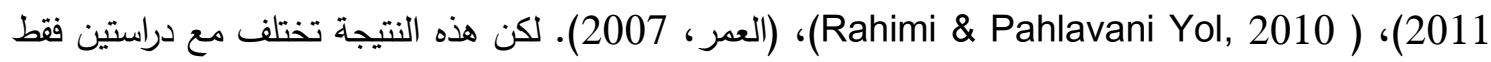
هما: (Sahadudhhen, I 2012)، (Greenidge \& DaCosta 2009) الخاصة بدولة جامايكا، ولعل ذلك يُفسر لخصوصية الاقتصاد الفلسطيني وما يعانيه من اختلالات هيكلية كونه اقتصاد ناشئ وهش ويتعرض للتدمير من قبل الاحتلال الصهيوني بثكل مستمر ، كذلك للحصار للمفروض عليه حصار بثكل دائم، من ناحية الحتية أخرى ينفق الجزء الأكبر من نصيب الفرد على السلع الاستهلاكية الضرورية والتي تعتبر غير مرنة للتغيرات في

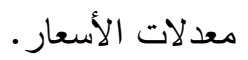

الفرضية الثالثة: وجود علاقة عكسية بين معدل سعر الصرف الاسمي ومعدل التضخم في الضفة الغربية من خلال نتائج التحليل في جدول (3)، يتضح أن معامل خط انحدار سعر الصرف قد بلدئ بلغ (2.1-) وهذا

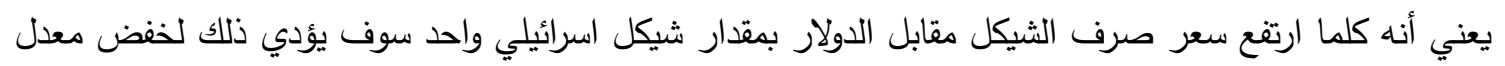
التضخم بمقدار 2.1\% في حال ثبات المتغيرات المستقلة الأخرى وهذا يتفق مع فرضية الدراسة ويوافق النظرية

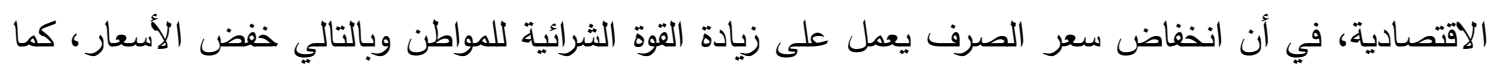

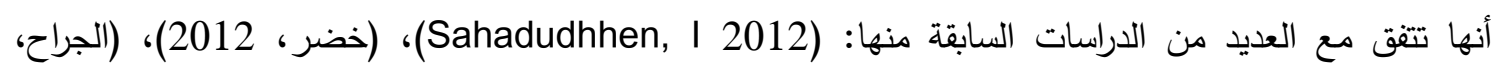
2011)، (إلهيتي وآخرون، 2010) في النتائج الخاصة بالاقتصاد الأردني وتختلف معها في النتائج الخاصة بالاقتصاد التركي، (الزهوي، 2010) في الأجل القصير، و و(Kim, 2001) • وتختلف معها العديد من الدراسات

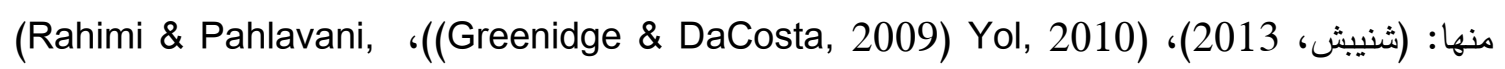
(2009، (Laryea \& Sumaila 2001)، وتعتبر هذه النتيجة منطقية في مثل حالة الاقتصاد الفلسطيني كونه

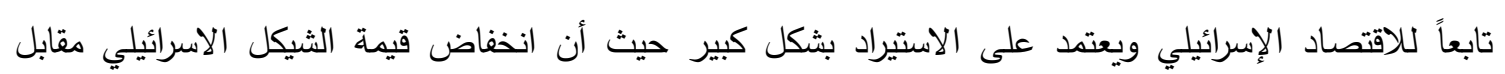

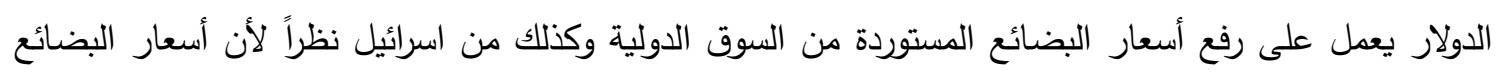

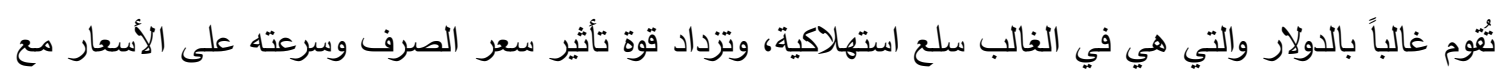
زيادة نسبة الواردات إلى إجمالي السلع الاستهلاكية.

ثانياً: نموذج قطاع غزة :

بعد إجراء العديد من المحاولات للوصول لأفضل نموذج قياسي تم تقدير النموذج التالي وكذلك تم التأكد من صلاحية النموذج المقدر والتحقق من شروط طريقة المربعات الصغرى وكانت النتائج كما يلي:

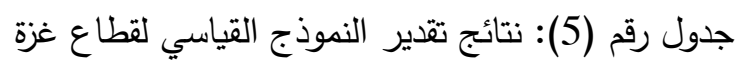

\begin{tabular}{|c|c|c|c|c|}
\hline \multicolumn{5}{|c|}{ Dependent Variable: INF } \\
\hline Variable & Coefficient & Std. Error & t-Statistic & Prob. \\
\hline C & -3.107725 & 1.037474 & -2.995472 & 0.0041 \\
\hline INF & 1.472418 & 0.353613 & 4.163924 & 0.0001 \\
\hline UNR & 0.070253 & 0.026985 & 2.603351 & 0.0118 \\
\hline GR & -0.037112 & 0.016550 & -2.242424 & 0.0290 \\
\hline $\mathbf{R}^{2}=\mathbf{0 . 6 3 3}$ & Adj. $\mathbf{R}^{\mathbf{2}}=\mathbf{0 . 2 9}$ ، & $\mathbf{D W}=\mathbf{1 . 8 4}$ ، & $\mathbf{F}=\mathbf{9 . 2 2}$ ، Prob.=0.000 \\
\hline
\end{tabular}

بحيث يصبح النموذج القياسي لقطاع غزة على الثكل التالي: $I N F_{g a}=-3.107-0.03 G R+0.07 U N R+1.47 I N F_{W o}+\varepsilon_{t}$ 
أيضاً هنا تم استخدام النموذج في تفسير العلاقة بين المتغيرات المستقلة والمتغير التابع للتأكد من صحة النموذج المقدر، وذلك من خلال اختبار مدى تحقق شروط طريقة المربعات الصغرى، وكذلك جودة النموذج

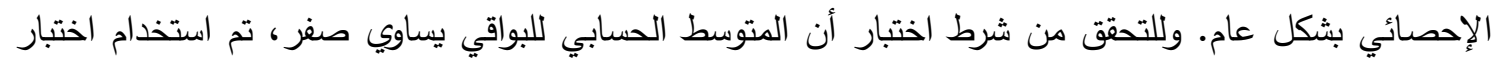

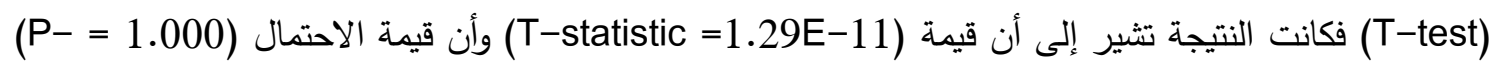

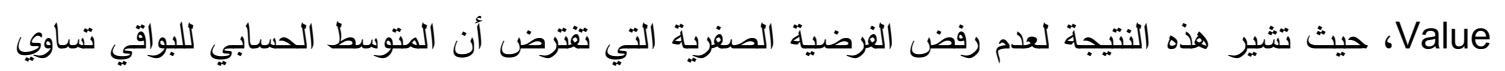

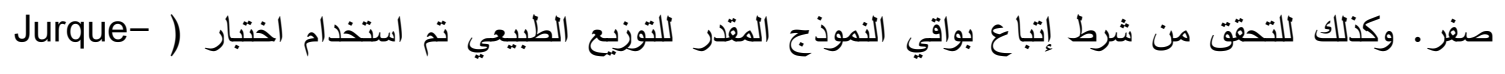

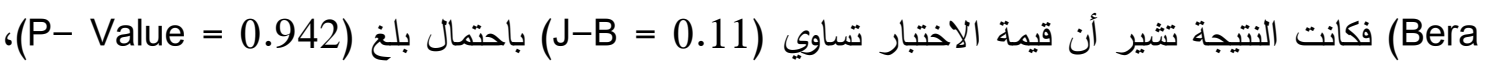
ويتضح من ذلك قبول الفرض العدمي الذي ينص على أن بواقي النموذج المقدر تتبع التوزيع الطبيعي. وأيضاً تم

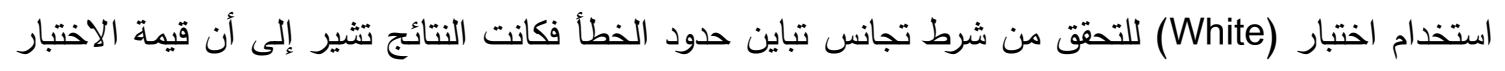
تبلغ (N*R-squared=9.29) باحتمال (P-value = 0.4108) وهذه النتيجة تدعم قبول الفرضية الصفرية التي تتص على تجانس تباين حدود الخطأ. وللتحقق من عدم وجود مشكلة ارتباط ذاتي في حدود الخطأ للنموذج

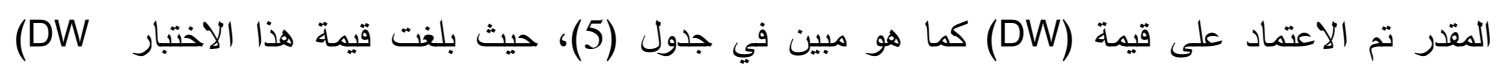

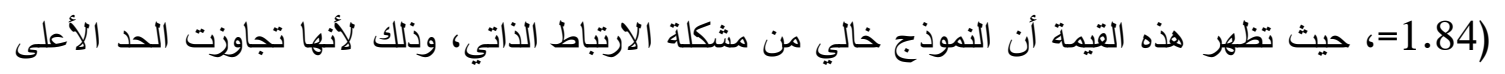
للقيمة الجدولية (du = 1.52) وبالتالي خلو النموذج المقدر من هذه المشكلة. وفيما يتعلق بمشكلة التداخل خطي

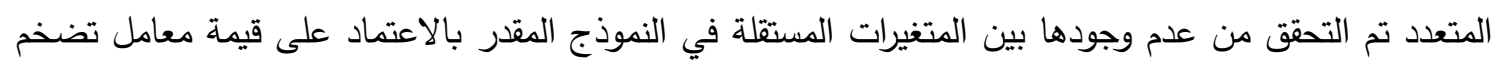
التباين (Variance Inflation Factors - VIF)، وقد تم حساب معامل التضخم لمتغيرات النموذج فكانت النتائج كما يلي:

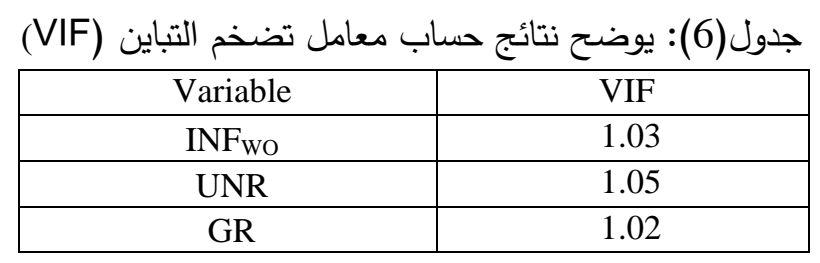

حيث تشير النتائج في الجدول (6) إلى أن قيمة (5IF > 5IF) وذلك لجميع المتغيرات، وهذا مؤشر واضح

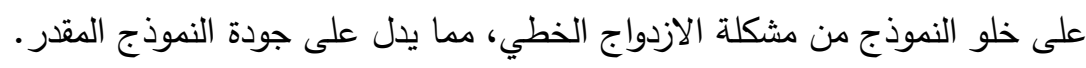

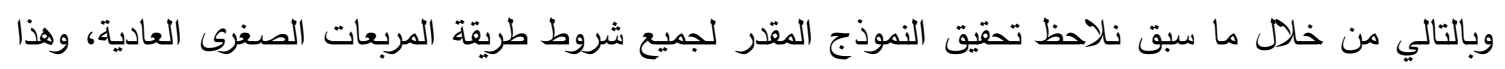
دليل واضح على جودة النموذج المقدر وسلامته من أي خلل قياسي، وبالتالي يمكن الاعتماد على نتائجه وتقسيرها بما يتناسب مع الواقع الاقتصادي.

اختبار الفرضيات والتفسير الاقتصادي لنموذج قطاع غزة:

الفرضية الأولى: وجود علاقة طردية بين معدل التضخم العالمي ومعدل التضخم في قطاع غزة النّان

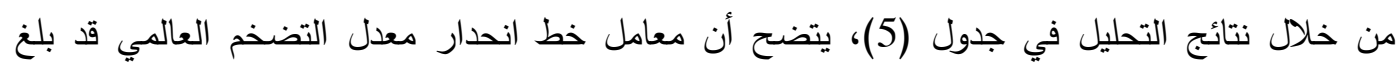

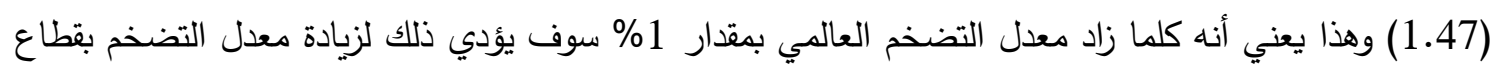
غزة بمقدار 1.47\% وحدة في حال ثبات المتغيرات المستقلة الأخرى، حيث تتفق هذه النتيجة مع النظرية الاقتصادية في أن ارتفاع أسعار المستوردات يعمل على رفع مستوى التضخم المحلي، كذلك تتفق هذه النتيجة مع هذئ العديد من الدراسات السابقة ومنها: (الجراح، 2011)، (الهجهوج، 2009)، 
(Phan \& Others, 2007)، (Khani, 2009). حيث أن هذه النتيجة تعكس واقع قطاع غزة في اعتماده على أسعار السلع القادمة من مصر نظراً لعدم وجود بدائل قادمة من إسرائيل في ظل الحصار المفروض على على فلى القطاع حيث شهد معدل التضخم ارتفاعاً ملحوظاً وغير مسبوق عام 2008 بنسبة 13.9 \% 13ن في قطاع غزة، وذلك على خلفية موجة الغلاء والارتفاع في الأسعار العالمية.

الفرضية الثانية: وجود علاقة طردية بين معدل النمو الاقتصادي ومعدل التضخم في قطاع غزة

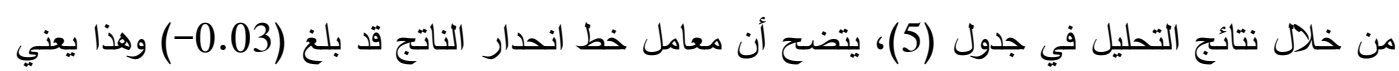

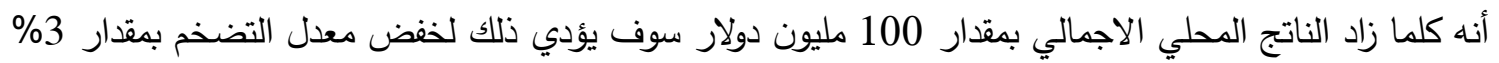
في حال ثبات المتغيرات المستقلة الأخرى، بالتالي تختلف هذه النتيجة مع النظرية الاقتصادية في العلاقة الطردية

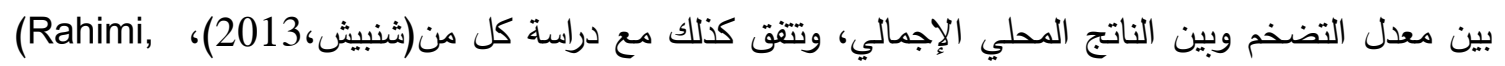

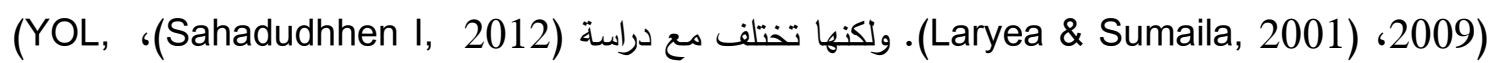

الفرضية الثالثة: وجود علاقة عكسية بين معدل البطالة ومعدل التضخم في قطاع غزة

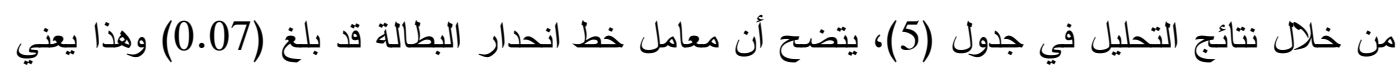

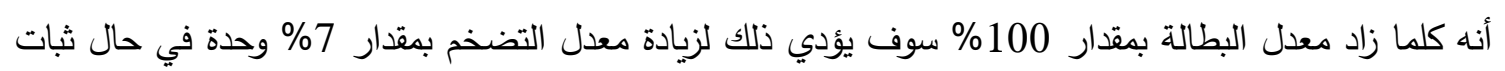
المتغيرات المستقلة الأخرى، وتخالف هذه النتيجة النظرية الاقتصادية الكلاسيكية في العلاقة العكسية بين معدل

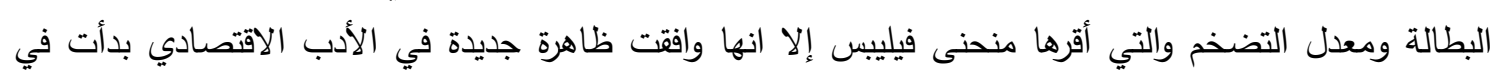

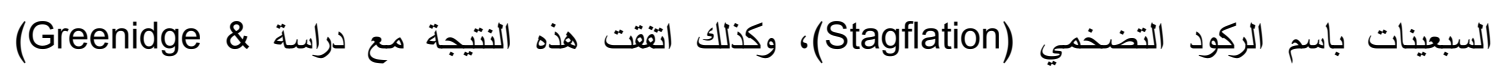
فaCosta, 2009)

$$
\text { (هتهات (ه) (ه) }
$$

النتائج

تم التوصل إلى النتائج التالية:

1. أن معدل التضخم المتحقق في الأراضي الفلسطينية يخفي الكثير من التتاقضات، حيث في الوقت الذي شهدت فيه مستويات الأسعار في الضفة الغربية ارتفاعاً، تراجعت مستويات الأسعار في قطاع غزة، مما يعكس حجم الإنم الاختلاف في الظروف الاقتصادية السائدة في المنطقتين. 2. بينت نتائج اختبار جوهانسن وجود علاقة توازنية طويلة الأجل بين متغيرات الدراسة وأنها لا تبتعد كثيراً عن الأن بعضها البعض في الأجل الطويل، بحيث تظهر سلوكا متشابهاً.

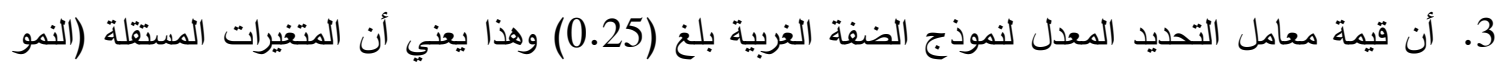

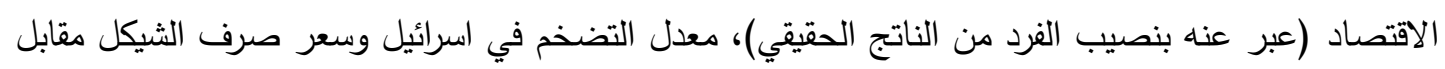

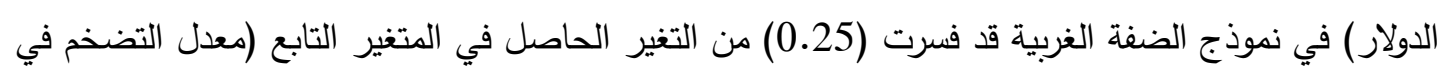
الضفة الغربية)، والنسبة المتبقية (0.75) ترجع لعوامل أخرى لم تدخل في النموذج أهمها عدم الاستقرار السياسي. 
4. أن قيمة معامل التحديد المعدل لنموذج قطاع غزة بلغ (0.29) وهذا يعني أن المتغيرات المستقلة (النمو الاقتصادي (عبر عنه بالناتج المحلي الاجمالي الحقيقي)، معدل التضخم في العالمي ومعدل البطالة) في نموذج قطاع غزة قد فسرت (0.29) من التغير الحاصل في المتغير التابع (معدل التضخم في قطاع غزة)، والنسبة المتبقية (0.71) ترجع لعوامل أخرى لم تدخل في النموذج أهمها الحصار المفروض على فلى القطاع

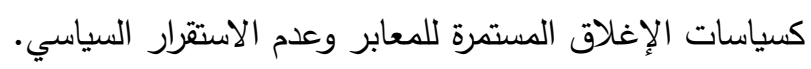

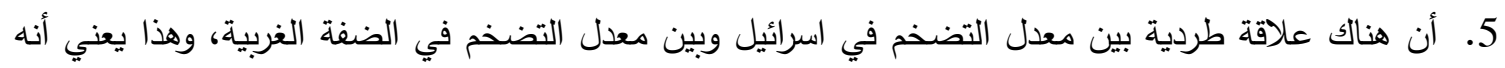

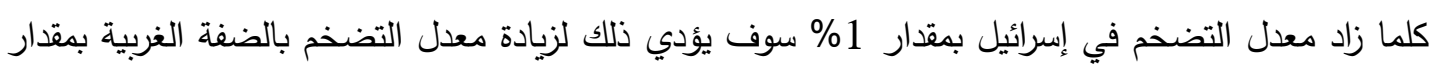
0.62 في حال ثبات المتغيرات المستقلة الأخرى.

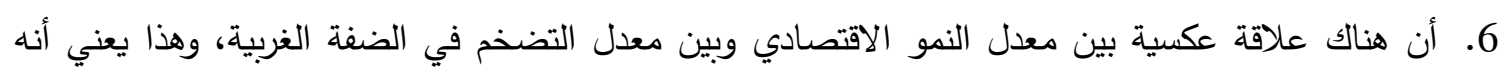
كلما زاد نصيب الفرد الحقيقي من الناتج بمقدار 100 دولار سينخفض معدل التضخد فئ في الضفة بمقدار 0.8\% في حال ثبات المتغيرات المستقلة الأخرى. 7. أن هناك علاقة عكسية بين معدل سعر صرف الثيكل مقابل الدولار وبين معدل التضخم في الضفة الغربية،

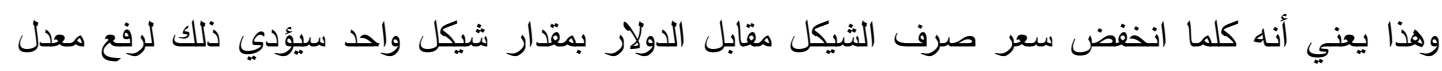
التضخم في الضفة بمقدار 2.1\% في حال ثبات المتغيرات المستقلة الأخرى، وهذا يعود إلى أن نسبة كبيرة من الواردات هي من السلع الأساسية والضرورية. 8. أن هناك علاقة طردية بين معدل التضخم العالمي وبين معدل التضخم في قطاع غزة، وهذا يعني أنه كلما

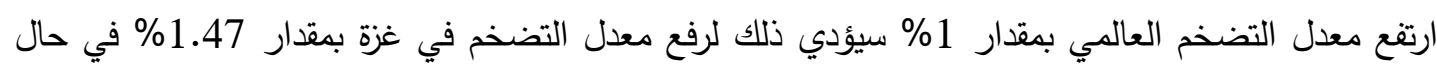
ثبات المتغيرات المستقلة الأخرى. 9. أن باقي المتغيرات (التسهيلات الائتمانية، سعر الفائدة، معدل الأجور) كانت غير دالة احصائياً، وهذا يعكس عدم وجود سياسة نقدية لعدم وجود عملة وطنية. 10. أن هناك علاقة عكسية بين معدل النمو الاقتصادي وبين معدل التضخم في قطاع غزة، وهذا يعني أنه كلما ارتفع الناتج المحلي الحقيقي بمقدار 100مليون دولار سيؤدي ذلك لخفض معدل التضخم في غزة بمقدار 3. في حال ثبات المتغيرات المستقلة الأخرى. 11.أن هناك علاقة طردية بين معدل البطالة وبين معدل التضخم في قطاع غزة، وهذا يعكس حالة الركود

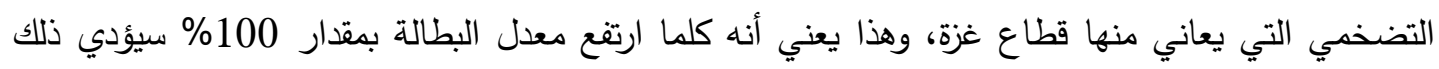
لرفع معدل التضخم في غزة بمقدار 7\% وذلك في حال ثبات المتغيرات المستقلة الأخرى.

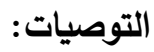

توصي الاراسة بمجموعة من التوصيات وهي: 1. العمل على ضرورة إصدار عملة وطنية إذا توفرت الثروط لذلكه، بحيث تتبع نظام الصرف الثابت مع عملة دولة مستقرة اقتصادياً ولها علاقات تجارية مع السلطة الفلسطينية، لكي نجنب الاقتصاد الفلسطيني حالة

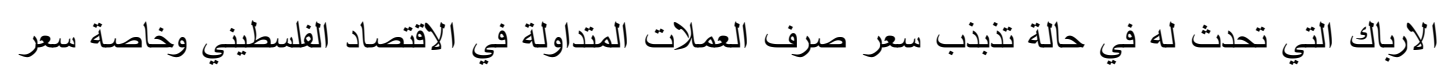
صرف الدولار مقابل الشيكل.

2. يتوجب على السلطة الفلسطينية اتخاذ الإجراءات الكفيلة بالقضاء على معدلات البطالة المرتفعة، من خلال تثجيع المشروعات التي تستخدم أيدي عاملة بكثرة كشاريع القطاع الزراعي. 
3. ضرورة دعم القطاعات الاقتصادية والتتموية المنتجة وتقديم الإعانات اللازمة لها، لتقليل الاعتماد على

الواردات وخاصة الاستهلاكية منها.

4. على السلطة الفلسطينية أن تراجع اتفاقياتها الاقتصادية الموقعة مع اسرائيل، وخاصة التجارية منها، لأنها تقف عائقا في سبيل تطور الاقتصاد الفلسطيني ولتقليل حدة التبعية للاقتصاد الاسرائيلي.

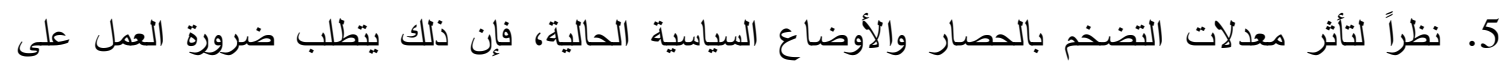
التخفيف من حدة التأثير السلبي للأوضاع السياسية من خلال حث المجتمع الدولي على الضغط على إسرائيل لتخفيف الحصار وذلك لتحفيز النشاط الاقتصادي.

إلهيتي، أحمد، وأخرون، (2010). أثر تقلبات أسعار الصرف في معدلات التضخم في الاقتصاد الأردني والتركي،

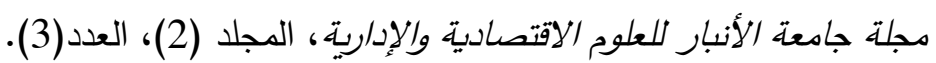

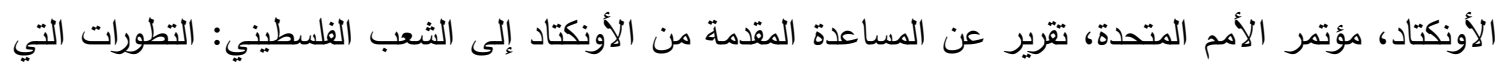
يثهده اقتصاد الأرض الفلسطينية المحتلة، 2012. الجراح، محمد، (2011). مصادر التضخم في المملكة العربية السعودية "دراسة قياسية باستخدام مدخل اختبارات

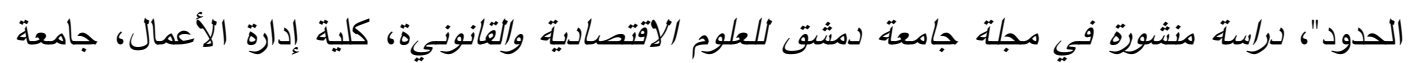
الملك سعود، الرياض. المبك.

الجلال، أحمد، (2006). دور السياسات النقدية والمالية في مكافحة التضخم في البلدان النامية: دراسة حالة الجمهورية اليمنية للفترة 1990-2003، رسالة ماجستير غير منشورة، قسم علوم التسيير، كلية العلوم الاقتصادية وعلوم التسيير، جامعة الجزائر، الجزائر • الجمانه

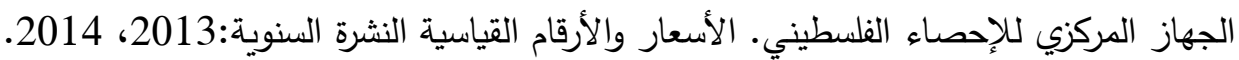

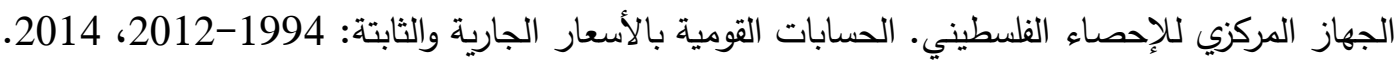
الجهاز المركزي للإحصاء الفلسطيني. كتاب فلسطين الإحصائي السنوي، 2014.

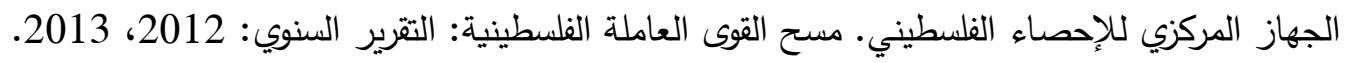

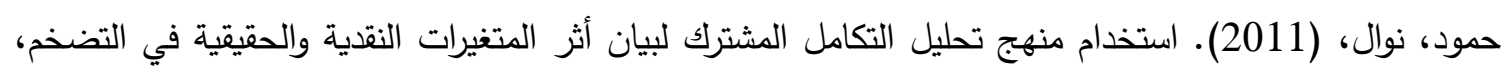
دراسة منشورة في مجلة جامعة الأنبار للعلوم الاقتصادية والادارية، قسم نظم المعلومات الإدارية، كلية الإدارة والاقتصاد، جامعة الموصل، العراق. خضر ، زاهر، (2012). تأثير سعر الصرف على المؤشرات الكلية للاقتصاد الفلسطيني (1994-2010)، رسالة ماجستير غير منشورة، قسم الاقتصاد، كلية الاقتصاد والعلوم الإدارية، جامعة الأزهر ، غزة.

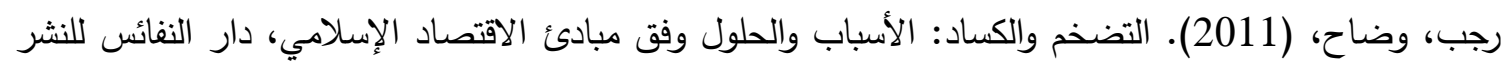
والتوزيع، بيروت، لبنان. زكي، رمزي، (1980). مشكلة التضخم في مصر أسبابها ونتائجها مع مقترحات لمكافحة الغلاء، الهيئة المصرية

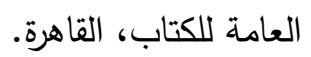


الزهوي، حسين عبد المنعم، (2010). دراسة اقتصادية قياسية لمحددات التضخم في مصر خلال الفترة (-2006 1986)، رسالة ماجستير غير منشورة، قسم الاقتصاد، كلية الاقتصاد والعلوم السياسية، جامعة القاهرة،

$$
\text { جمهورية مصر العربية. }
$$

سامويلسون، بول ، نوردهاوس، ويليام، (2006). الاقتصاد، الدار الاهلية للنشر والتوزيع ، عمان، الأردن.

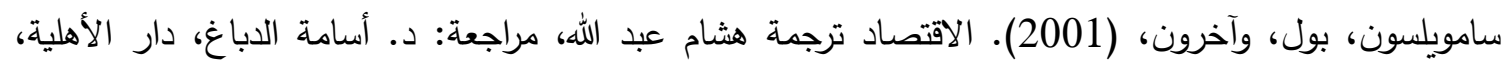
عمان، الأردن. سلطة النقد الفلسطينية، التقرير السنوي الاردن. 2015، 2014، 2013، 2010، 2006. السمهوري، محمد، (2000). اقتصاديات النقود والبنوك، جامعة الأزهر ، فلسطين. الثبول، نايف، (1981). التضخم في الاقتصاد الأردني -دراسة تحليلية أسبابه وقياسه وعلاجه، جسالة ماجستير الأهر، غير منشورة، كلية التجارة جامعة عين شمس. شلتوت، حافظ محمود، (2008). اقتصاديات النقود والبنوك، مطابع الدار الهندسية، القاهرة. شنبيش، محمد، (2013). دراسة العلاقة بين التضخم وعرض النقود وسعر الصرف في الاقتصاد الليبي خلال

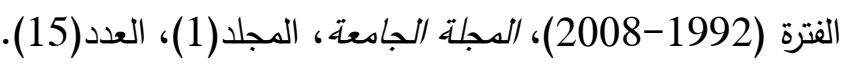

صافي، سمير، (2015). مقدمة في تحليل نماذج الانحدار باستخدام EVIEWS، الناشر: مكتبة آفاق، غزة فلسطين. صندوق النقد الدولي ( 2003)، التضخم - تحقيق التوازن السليم. مجلة التمويل التتمية، واشنطن العاصمة. صندوق النقد الدولي، تقرير 2014. عبد القادر، السيد متولي، (2007). اثتقاق نموذج تصحيح الخطأ من اختبار التكامل المتساوى لجوهانسن إطار نظري ومثال تطبيقي باستخدام EViews5، المعهد العالي للحاسبات ونظم المعلومات الإدارية وعلوم الإدارة، مصر .

عطية، عبد القادر، (2005). الحديث في الاقتصاد القياسي بين النظرية والتطبيق، الدار الجامعية، الإسكندرية. العمر، حسين، (2007). محددات التضخم بدولة الكويت، دراسة منشورة في مجلة العلوم الاقتصادية والإدارية، كلية الدراسات التجارية، الكويت.

الفريق الأهلي لدعم شفافية الموازنة (فلسطين). رؤية الفريق الأهلي لدعم شفافية الموازنة حول "السياسة المالية

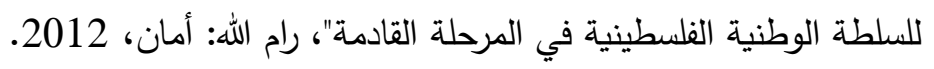
المصبح، عماد الدين، (2006). محددات التضخم في سورية خلال الفترة 1970- 2004، دراسة منهاة منشورة في مجلة العلوم الاجتماعية، جامعة الكويت، مجلس النشر العلمي، الكويت. معهد أبحاث السياسات الاقتصادية الفلسطيني (ماس). المراقب الاقتصادي والاجتماعي، العدد(34)، مقلد، رمضان، والفيل، أسامة، (2012). النظرية الاقتصادية الكلية، دار التعليم الجامعي، الاسكندرية، مصر .

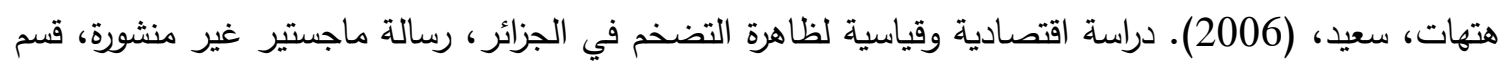
العلوم الاقتصادية، كلية الحقوق والعلوم الاقتصادية، جامعة قاصدي مرياح، الجزائر .

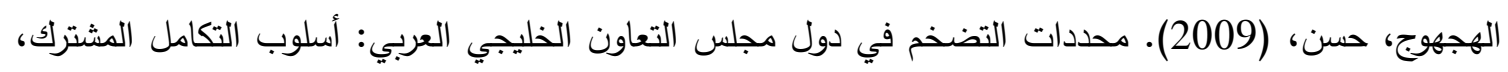
قسم الاقتصاد والتخطيط، كلية العلوم الإدارية والتخطيط، جامعة الملك فيصل.

\section{References}


Abdelkader, Al Said Metwally. (2007). Derivation of the Error Correction Model from The Johansen Isometric Test. A Theoretical Framework and an Applied Example Using Eviews5. Higher Institute of Computers, Management Information Systems and Management Sciences, Egypt. (in Arabic)

Abdul Aleem Khan et. Al. (2007). Determinants of Recent Inflation in Pakista, Social Policy and Development Center: Karach, Munich Personal RePEcArchive (MPRA), Working Paper No. 16254. (in Arabic)

Alareeni, B., \& Branson, J. (2011). The relative performance of auditors' going-concern opinions and statistical failure prediction models in Jordan. Accountancy \& Bedrijfskunde, 31 (8), 23-35

Alareeni, B., \& Branson, J. (2013). Predicting listed companies' failure in jordan using altman models: a case study. International Journal of Business and Management, 8(1), 113-126.

Alareeni, Deghash. (2016). Applicability of the balanced scorecard to assess performance of al-aqsa media network institution in gaza strip. IUG Journal of Economics and Business, 24(3), 21-46

Al-Hajhouj, Hassan. (2009). Determinants of Inflation in the Arab Gulf Cooperation Council Countries: Method of Joint Integration, Department of Economics and Planning, College of Administrative Sciences and Planning, King Faisal University. (in Arabic)

Al-Jalal, Ahmad (2006). The Role of Monetary and Financial Policies in Combating Inflation in Developing Countries: A Case Study of the Republic of Yemen for the Period 1990-2003. [Unpublished Master Thesis], Department of Management Sciences, Faculty of Economic Sciences and Management Sciences, University of Algiers, Algeria. (in Arabic)

Al-Jarrah, Muhammad. (2011). Sources of inflation in the Kingdom of Saudi Arabia "A study using the entry of boundary test, Journal of Economic and Legal Sciences. (in Arabic)

Al-Musbah, Imad Al-Din. (2006). Determinants of inflation in Syria during the period 1970 - 2004. Journal of Social Sciences, Kuwait University, Scientific Publishing Council, Kuwait. (in Arabic)

Al-Omar, Hussain. (2007). Determinants of Inflation in the State of Kuwait. Journal of Economic and Administrative Sciences, College of Business Studies, Kuwait. (in Arabic)

Al-Samhouri, Muhammad. (2000). Money and Banking Economics, Al-Azhar University, Palestine.

Al-Shboul, Naif, (1981). Inflation in the Jordanian Economy - An Analytical Study of Its Causes, Measurement and Treatment. [Unpublished Master Thesis], Faculty of Commerce, Ain Shams University. (in Arabic)

Al-Zahwi, Hussein Abdel-Moneim. (2010). An Econometric Study of the Determinants of Inflation in Egypt During the Period (1986 - 2006). [Unpublished Master's Thesis], Cairo University, Egypt. (in Arabic)

Attia, Abdelkader. (2005). Modern Econometrics, Between Theory and Practice, University House, Alexandria. (in Arabic)

Bayo, F. (2005). Determinants of inflation in Nigeria: An empirical analysis. International Journal of Humanities and Social Science, 1(18), 262-271.

Bernanke, B. (2005). Inflation in Latin America-Anew Era? Paper presented at theStanford Institute for Economic Policy Research Economic Summit, February. 
El-hiti, et. Al., (2010). The effect of exchange rate fluctuations on inflation rates in the Jordanian and Turkish economies. Anbar University Journal of Economic and Administrative Sciences, 2(3). (in Arabic)

Greenidge, K., \& DaCosta, D. (2009). Determinants of inflation in selected caribbean countries. Journal of Business, Finance \& Economics in Emerging Economies, 4(2), 371-397.

Gujarati, Damodar N. (2004). Basic Econometrics, McGraw companies.

Hammoud, Nawal. (2011). The use of the joint integration analysis methodology to demonstrate the impact of monetary and real variables on inflation. Anbar University Journal of Economic and Management Sciences. (in Arabic)

Hathat, Saeed. (2006). An Economic and Measurement Study of the Phenomenon of Inflation in Algeria. [Unpublished Master's Thesis], Kassdi Mariah University, Algeria. (in Arabic)

International Monetary Fund. (2003). Inflation - Achieving the Right Balance. Development Finance Journal, Washington, DC.

International Monetary Fund. (2014) Report. (in Arabic)

Khader, Zahir. (2012). The effect of the exchange rate on the overall indicators of the Palestinian economy (1994-2010). [Unpublished Master's Thesis], Al-Azhar University, Gaza. (in Arabic)

Laryea, Samuel \& R. Sumaila, Ussif. (2001). Determinants of Inflation in Tanzania, Development Studies and Human Rights (DSHR), Working Paper No. 12.

Mukalled, Ramadan, and the Alfeel, Osama. (2012). Macroeconomic Theory, University Education House, Alexandria, Egypt. (in Arabic)

Pahlavani, M., \& Rahimi, M. (2009). Sources of inflation in Iran: An application of the ARDL approach. International Journal of Applied Econometrics and Quantitative Studies, 6(1), 61-76.

Palestine Monetary Authority, Annual Report 2015, 2014, 2013, 2010, 2006.

Palestinian Central Bureau of Statistics. (2013). Palestinian Labor Force Survey: Annual Report: 2012, 2013. (in Arabic)

Palestinian Central Bureau of Statistics. (2014). National Accounts at Current and Constant Prices: 1994-2012, 2014. (in Arabic)

Palestinian Central Bureau of Statistics. (2014). Palestine Statistical Yearbook. (in Arabic)

Palestinian Central Bureau of Statistics. (2014). Prices and Index Numbers Annual Bulletin: 2013, 2014.

Rajab and Waddah. (2011). Inflation and Depression: Causes and Solutions According to the Principles of Islamic Economics, Dar Al-Nafaes for Publishing and Distribution, Beirut, Lebanon. (in Arabic)

Safi, Samir. (2015). Introduction to Regression Model Analysis Using EVIEWS, Publisher: Afaq Library, Gaza-Palestine. (in Arabic)

Sahadudheen, I. (2012). A cointegration and error correction approach to the determinants of inflation in India. International Journal of Economic Research, 3(1), 105-112.

Samuelson, Paul, Nordhouse, William. (2006). Economy, the National House for Publishing and Distribution, Amman, Jordan.

Shaltout, Hafez Mahmoud. (2008). The Economics of Money and Banking, Engineering House Press, Cairo. (in Arabic)

Shanbeesh, Muhammad. (2013). A study of the relationship between inflation, money supply and the exchange rate in the Libyan economy during the period (19922008). The University Journal, 1(15). (in Arabic) 
The Palestinian Economic Policy Research Institute. (2013). The Economic and Social Monitor, No. (34). (in Arabic)

UNCTAD (2012). United Nations Conference, Report on UNCTAD Assistance to the Palestinian People: Developments in the Economy of the Occupied Palestinian Territory.

Yol, MarialAwou (2010). Determinants of Inflation in Sudan: An EmpircalAnalysis, Policies, Research and Statistics Department, The Central Bank of Sudan.

Zaki, Ramzi (1980). The Problem of Inflation in Egypt, its Causes and Consequences, with Proposals to Combat High Prices, the Egyptian General Book Authority, Cairo. (in Arabic)

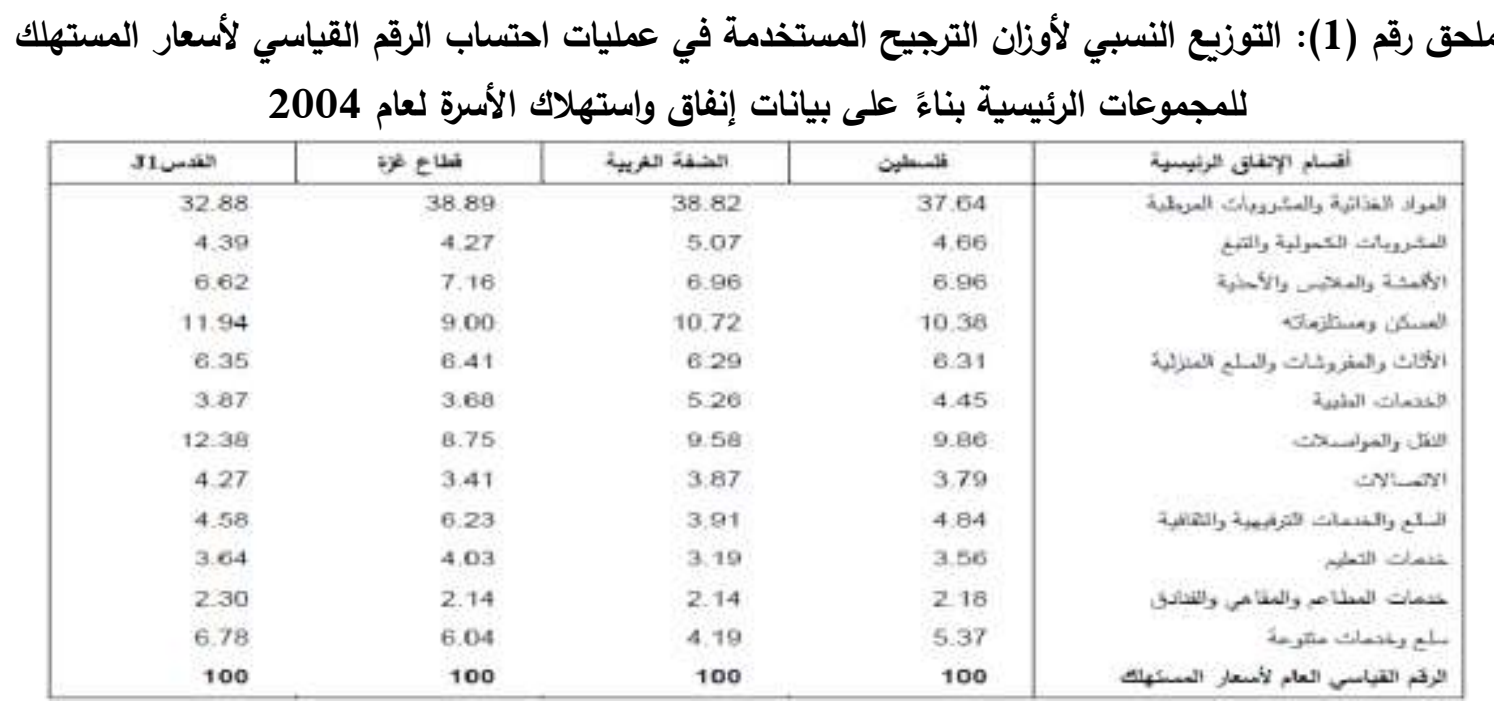

المصدر : الجهاز المركزي للإحصاء الفلسطيني: http:/www.pcbs.gov.ps.

ملحق رقم (2) الرقم القياسي لأسعار المستهلك ومعدل التضخم خلال الفترة (2000-2014)

\begin{tabular}{|c|c|c|c|c|c|c|c|}
\hline INFw & INFg & INFp & INFw & INFg & INFp & السنة \\
\hline 9.81 & 13.97 & 9.89 & 2008 & 3.21 & 2.97 & 2.79 & 2000 \\
\hline 0.57 & 4.42 & 2.75 & 2009 & 2.62 & -1.03 & 1.23 & 2001 \\
\hline 4.24 & 1.71 & 3.75 & 2010 & 6.08 & 2.08 & 5.71 & 2002 \\
\hline 3.54 & 0.58 & 2.88 & 2011 & 4.3 & 2.47 & 4.4 & 2003 \\
\hline 4.08 & 0.48 & 2.78 & 2012 & 2.89 & 3.18 & 3.01 & 2004 \\
\hline 3.1 & -0.77 & 1.72 & 2013 & 4 & 2.45 & 4.11 & 2005 \\
\hline 1.2 & 2.9 & 1.7 & 2014 & 5.02 & 4.64 & 3.84 & 2006 \\
\hline & & & & 0.75 & 1.56 & 1.86 & 2007 \\
\hline
\end{tabular}

المصدر: الجهاز المركزي للإحصاء الفلسطيني. الأسعار والأرقام القياسية النشرة السنوية:2013،2014. الجهاز المركزي للإحصاء الفلسطيني: http://www.pcbs.gov.ps/. وسلطة النقد الفلسطينية، 2015. التقرير السنوي لعام 2014. 
تم توفير التمويل الأساسي لهذا البحث من قبل سلطة النقد الفلسطينية، ومن خلال اتفاقية التعاون بينها وبين الكلية الجامعية في مجال دعم البحث العلمي في فلسطين. 